\section{Improving the CROPGRO-Tomato Model for Predicting Growth and Yield Response to Temperature}

\author{
Kenneth J. Boote ${ }^{1}$ \\ University of Florida, Agronomy Department, 304 Newell Hall, Gainesville, \\ FL 32611-0500
}

Maria R. Rybak

INTA, EEA Cerro Azul, Misiones, Argentina

Johan M.S. Scholberg

Wageningen University, Wageningen, The Netherlands

James W. Jones

University of Florida, Agricultural and Biological Engineering Department, Frazier Rogers Hall, Gainesville, FL 32611-0500

Additional index words. cardinal temperatures, crop model parameters, development, fruit-set, fruit growth, leaf area, dry matter accumulation, fresh weight yield, Lycopersicon esculentum Mill

\begin{abstract}
Parameterizing crop models for more accurate response to climate factors such as temperature is important considering potential temperature increases associated with climate change, particularly for tomato (Lycopersicon esculentum Mill.), which is a heatsensitive crop. The objective of this work was to update the cardinal temperature parameters of the CROPGRO-Tomato model affecting the simulation of crop development, daily dry matter (DM) production, fruit set, and DM partitioning of field-grown tomato from transplanting to harvest. The main adaptation relied on new literature values for cardinal temperature parameters that affect tomato crop phenology, fruit set, and fruit growth. The new cardinal temperature values are considered reliable because they come from recent published experiments conducted in controlled-temperature environments. Use of the new cardinal temperatures in the CROPGRO-Tomato model affected the rate of crop development compared with prior default parameters; thus, we found it necessary to recalibrate genetic coefficients that affect life cycle phases and growth simulated by the model. The model was recalibrated and evaluated with 10 growth analyses data sets collected in field experiments conducted at three locations in Florida (Bradenton, Quincy, and Gainesville) from 1991 to 2007. Use of modified parameters sufficiently improved model performance to provide accurate prediction of crop and fruit DM accumulation throughout the season. Overall, the average root mean square error (RMSE) over all experiments was reduced $44 \%$ for leaf area index, $71 \%$ for fruit number, and $36 \%$ for both aboveground biomass and fruit dry weight simulations with the modified parameters compared with the default. The Willmott $d$ index was higher and was always above 0.92 . The CROPGRO-Tomato model with these modified cardinal temperature parameters will predict more accurately tomato growth and yield response to temperature and thus be useful in model applications.
\end{abstract}

Crop growth simulation models are emerging technological tools with potential uses for interpreting research (Boote et al., 1996, 2010) and for production management to monitor irrigation and nitrogen $(\mathrm{N})$ uses (Paz et al., 2007; Rinaldi et al., 2007). Before the use of crop growth models for such research or management purposes, it is important that the models be accurately parameterized with the most currently available data from the literature before calibrating and validating them with field measures to ensure their robustness of

Received for publication 13 Mar. 2012. Accepted for publication 31 May 2012.

${ }^{1}$ To whom reprint requests should be addressed; e-mail kjboote@ufl.edu.

CROPGRO-Tomato model was adapted by Scholberg et al. (1997) to simulate field-grown tomato. However, during the initial model adaptation, limited information was available to calibrate temperature response functions. Another reason for re-evaluating the performance of DM and carbon balance of the CROPGRO-Tomato model is that we recently created a module for predicting fresh tomato weight and fruit size, which will be added to the Decision Support System for Agrotechnology Transfer (DSSAT) software. This fruit fresh weight module has its origins in the crop carbon balance; therefore, biases in crop and fruit DM predictions will be propagated to fruit fresh weight prediction as well, which in turn could affect fruit size simulation. For this reason, the objectives of this work are to: 1) use recent literature to update temperature-based crop model parameters of the CROPGRO-Tomato model; and 2) recalibrate and evaluate the model for more accurate simulation of temperature effects on crop development, daily DM production, and DM partitioning of tomato from transplanting to harvest.

Literature Review: Toward a Modeling Analysis of Temperature Effects on

Tomato, A Conceptual Approach

During the entire conceptual process, the systematic approach for crop model improvement proposed by Boote et al. (2002) was followed and can be summarized in three steps. First, an update of the cardinal temperature parameters was performed, replacing the values used by Scholberg et al. (1997) with values reported in recent literature, which are summarized in this article. Important modified species coefficients included cardinal temperatures for pre-anthesis and post-anthesis phases as well as cardinal temperatures for leaf appearance rate, leaf photosynthesis, fruit set, and fruit growth rate. The photosynthesis option in the CROPGRO model used for this article is based on hourly leaf-level photosynthesis scaled to canopy assimilation (an obsolete radiation use efficiency-based daily canopy assimilation option is available but is not discussed here). Second, life cycle phase durations and other parameters were calibrated against growth analyses data from field experiments. Third, the quality of the model predictions was evaluated using statistics such as RMSE and the Willmott index as evaluation criteria (Willmott, 1981). Calibration was performed in the following order with phenology adjusted first followed by recalibration of growth traits. The work consisted of two key efforts for which the methodology is presented in more detail here. The first included a critical review of currently available information on temperature response of tomato for crop development, growth, and production as related to development of generic functions used in crop growth models. The second component presents the procedures to integrate this information for the recalibration of the temperature response functions of the CROPGRO-Tomato model along with a comparison of model growth and yield performance between the previous and adapted model versions.
Developing Literature-based

Temperature Coefficients for the CROPGRO-Tomato Model

The purpose of the following section is to present a methodological framework for 
modified model input parameters through a thorough re-evaluation of the existing research. This is needed to quantify how temperature affects both vegetative and reproductive development, photosynthesis, DM partitioning, fruit set, and individual fruit growth rate.

To account for the dependence on temperature of several processes, the CROPGROTomato model uses four-point functions represented by four cardinal temperatures: 1) base temperature $\left(T_{b}\right)$, the temperature below which the rate of the process is zero; 2 ) Topt ${ }_{1}$, the lowest temperature at which maximum rate is attained; 3) Topt $_{2}$, the upper temperature at which maximum rate is sustained; and 4) maximal temperature (Tmax), at which rate falls to zero. The default (Version 4.0) version of CROPGRO uses the same values of cardinal temperatures for the three phenological phases (vegetative, early reproductive and late reproductive phases) and those values are 10, 28, and $55{ }^{\circ} \mathrm{C}$ for base, optimum (both $\mathrm{Topt}_{1}$ and Topt $_{2}$ ), and Tmax, respectively (Scholberg et al., 1997). The CROPGRO model has a read-in species file in which the sensitivities of these processes to temperature are described with various functions (Boote et al., 1998), particularly with emphasis on cardinal temperatures such as base temperature in which rate or progress is zero, optimum temperature (for fastest rate or progress), and upper failure point temperature. With the functions for crop development, there is linear interpolation of rate between these cardinal temperatures, although nonlinear (parabolic) interpolations are used for rate of fruit addition, fruit growth rate, and photosynthesis. It is also important to realize that these model functions use hourly temperature rather than daily mean, so the response based on hourly temperature is not necessarily a sudden change on reaching cardinal temperature thresholds.

We review the literature for cardinal temperatures affecting different growth and development processes that will be used in the modified version of the CROPGRO-Tomato model. First, we describe general concepts and relationships between temperature and crop development. Then we discuss specific cardinal temperatures for different growth processes in more detail as related to specific growth routines of the CROPGRO-Tomato model. With the goal of improving temperaturedependent processes in the CROPGRO-Tomato model, we modified the cardinal temperature parameters for phenology following Adams et al. (2001) and other references discussed in the literature review. In addition, cardinal temperature values that influence the effect of temperature on rate of fruit addition, fruit growth, seed growth rate, and photosynthesis also were modified. Table 1 summarizes the cardinal temperatures for both the default model and the modified values based on the literature for phenological development, fruit addition and pollination, fruit growth, and leaf photosynthesis of tomato.

Plant development. To predict plant development as a universal function of temperature, Monteith (1977) introduced the concept of thermal time, which is the summation of

Table 1. Modified cardinal temperature dependencies for tomato phenology, fruit and seed growth, and photosynthesis for the CROPGRO-Tomato model, default Version 4.0 values, and modified values in species file. ${ }^{\mathrm{z}}$

\begin{tabular}{|c|c|c|c|c|c|}
\hline \multirow{3}{*}{$\begin{array}{l}\text { Vegetative or reproductive process } \\
\text { (and literature source of cardinal temperatures) }\end{array}$} & & \multicolumn{4}{|c|}{$\begin{array}{c}\text { Cardinal } \\
\text { temperature value }\end{array}$} \\
\hline & & $\mathrm{T}_{\mathrm{b}}$ & Topt $_{1}$ & $\mathrm{Topt}_{2}$ & $\mathrm{Tmax}$ \\
\hline & & \multicolumn{4}{|c|}{------ $\left({ }^{\circ} \mathrm{C}\right)$} \\
\hline \multicolumn{6}{|l|}{ Rate of leaf (or truss) appearance (vegetative development) } \\
\hline & Default & 10 & 28 & 28 & 55 \\
\hline $\begin{array}{l}\mathrm{T}_{\mathrm{b}} \text { and } \mathrm{Topt}_{1} \text { (Adams et al., 2001) } \\
\text { Topt }_{2} \text { and Tmax (De Koning, 1994) }\end{array}$ & Modified & 7 & 22 & 28 & 48 \\
\hline
\end{tabular}

Rate of progress to anthesis/truss appearance rate (early reproductive development)

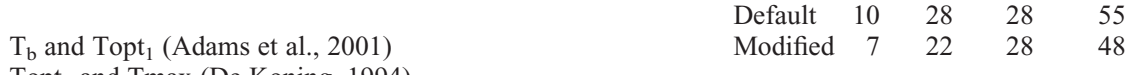

$\mathrm{Topt}_{2}$ and Tmax (De Koning, 1994)

Rate of fruit development and maturation (late reproductive development)

\begin{tabular}{|c|c|c|c|c|}
\hline & Default & 10 & 28 & 28 \\
\hline $\mathrm{T}_{\mathrm{b}}, \mathrm{Topt}_{1}$, and $\mathrm{Topt}_{2}$ (Adams et al., 2001) & Modified & 5.2 & 26 & 28 \\
\hline
\end{tabular}

$\mathrm{Topt}_{2}$ and Tmax (De Koning, 1994)

Relative effect of temperature on fruit addition and pollination

$\mathrm{T}_{\mathrm{b}}, \mathrm{Topt}_{1}$, and $\mathrm{Topt}_{2}$ (Adams et al., 2001)

$\begin{array}{lrrrr}\text { Default } & 6 & 8 & 28 & 30\end{array}$

$\mathrm{T}_{\max }$ (Benedictos and Yavari, 2000; Moore and Thomas, 1952)

Relative effect of temperature on individual fruit/seed growth rate

Topt $_{2}$ (Adams et al., 2001)

$\begin{array}{lllll}\text { Default } & 6 & 8 & 25.5 & 32\end{array}$

Rate of light-saturated leaf photosynthesis (L version)

$\mathrm{T}_{\mathrm{b}}$ (Byrd et al. 1995)

Topt $_{1}$ and Topt 2 (Heuvelink and Dorais, 2005)

Modified $\begin{array}{llll}6 & 22 & 25 & 32\end{array}$

${ }^{\mathrm{z}}$ Literature sources for cardinal temperatures are given. Some values were modified from literature values based on calibration to field data. When no attribution is given, values were estimated by analogy to other processes.

$\mathrm{T}_{\mathrm{b}}=$ base temperature; $\mathrm{Topt}_{1}=$ the lowest temperature at which maximum rate is attained; Topt $\mathrm{t}_{2}=\mathrm{the}$ upper temperature at which maximum rate is sustained; Tmax $=$ maximum temperature.

temperatures above a threshold called base temperature (Ferreira et al., 1997). Perry et al. (1997), for instance, used this concept to predict tomato harvest in the southeastern United States. However, reported base temperatures values for tomato ranged from 4 to $10{ }^{\circ} \mathrm{C}$ (Calado and Portas, 1987; Folker, 1979; Scholberg et al., 1997; Warnock and Isaacs, 1969). Warnock (1973), in Davis, CA, used a base temperature of $6{ }^{\circ} \mathrm{C}$ to calculate the degree-days accumulated from seeding to ripe fruit. The inconsistencies in the base temperature values may have several explanations, but one possible reason is that the base temperature is not identical for all crop development stages. Therefore, responses to temperature during the seedling phase, for example, may differ from responses during fruit setting or fruit ripening. However, one common base temperature is often considered for all stages of the crop. Another possibility is that cultivars may vary in cardinal temperatures. Another cause could be related to the methods and data sets for deriving the cardinal temperatures, as exemplified by reported base temperatures of 6,8 , and $10{ }^{\circ} \mathrm{C}$ obtained by Calado and Portas (1987) when estimated for three locations differing from warm early spring to a cool early spring in Portugal. They computed the base temperature with the intercept method. The hypothesis in crop modeling is that cardinal temperatures for
Table 2. Tomato plant age at transplanting in CROPGRO default Version 4.0 and calibrated values in the experimental file.

\begin{tabular}{|c|c|c|}
\hline \multirow[b]{2}{*}{ Experiment } & Default & Calibrated \\
\hline & -------- $\left(\right.$ days $\left.^{z}\right)$ & \\
\hline$\overline{\text { Bradenton } 1991}$ & 28 & 24 \\
\hline Bradenton 1992 & 28 & 25 \\
\hline Bradenton 1994 & 28 & 25 \\
\hline Bradenton 1995 & 28 & 28 \\
\hline Quincy 1995 (spring) & 28 & 27 \\
\hline Quincy 1995 (fall) & 28 & 25 \\
\hline Gainesville (1996) 1 & 28 & 28 \\
\hline Gainesville (1996) 2 & 28 & 28 \\
\hline Gainesville (2006) & 28 & 28 \\
\hline Gainesville (2007) & 28 & 29 \\
\hline
\end{tabular}

zPlant age in days, assuming $25^{\circ} \mathrm{C}$ optimum conditions in transplant greenhouses. Model entry requests transplant growth temperature and actual days of plant age at given temperature.

a given species and cultivar should hold constant across weather and sites. The failure to do so may be evidence of incorrect cardinal temperatures and temperature response equations. Another aspect to be considered is the type of function that a crop growth model uses to account for the temperature dependence of processes. The CROPGRO model computes hourly temperatures from the maximum and minimum temperature data using a sinusoidal function during the day plus a decay function 
at night that was shown to predict hourly temperature accurately (Parton and Logan, 1981). Although the development rate may have linear interpolation between cardinal temperatures, the daily rate is averaged over $24 \mathrm{~h}$ of simulated air temperatures moving smoothly throughout the day.

Vegetative development and early reproductive phase to anthesis. According to Van der Ploeg and Heuvelink (2005), the optimum temperature for early vegetative growth of tomato plants is $25^{\circ} \mathrm{C}$. Tomato vegetative development can be considered as the leaf appearance rate and it is also related to the truss appearance rate because the species is a sympodic with approximately one inflorescence every three leaves (Heuvelink, 2005). De Koning (1994) showed a linear increase of leaf appearance rate with increase in average air temperature, increasing from 0.2 leaf/d at $12{ }^{\circ} \mathrm{C}$ to a maximum of $0.5 \mathrm{leaf} / \mathrm{d}$ at $28^{\circ} \mathrm{C}$ and decreasing thereafter until reaching zero at $48^{\circ} \mathrm{C}$. According to Adams et al. (2001), vegetative development in tomato has an optimum temperature between $22^{\circ} \mathrm{C}\left(\mathrm{Topt}_{1}\right)$ and $26{ }^{\circ} \mathrm{C}$ $\left(\mathrm{Topt}_{2}\right)$. The base temperature for this phase according to their calculation is $7^{\circ} \mathrm{C}$.

A linear relation between flowering and air temperature has also been observed by Abreu et al. (2000). Truss appearance rate increased linearly from 0.11 to 0.17 truss/d when average temperature was raised from 17 to $23{ }^{\circ} \mathrm{C}$ (De Koning, 1994). According to De Koning (1993), the number of trusses per week is enhanced by temperature with 0.05 truss $/$ week $/{ }^{\circ} \mathrm{C}$. Adams et al. (2001) found the cardinal temperature values for the early reproductive phase (progression to anthesis) to be similar to that for vegetative development with a base temperature of $7.2^{\circ} \mathrm{C}$. They had no data to set Tmax. From all these sources and considering Adams et al. (2001) as the most carefully studied, we adopted 7 , 22, 28, and $48{ }^{\circ} \mathrm{C}$ for $\mathrm{T}_{\mathrm{b}}$, Topt ${ }_{1}$, Topt ${ }_{2}$, and Tmax, respectively, as cardinal temperatures for vegetative and early reproductive development in the modified CROPGRO-Tomato model parameter input file (Table 1).

Late reproductive phase, anthesis to maturity, and fruit growth duration. A critical temperature sum needs to be reached over an individual fruit growth period for fruits to achieve maturity (Heuvelink, 2005). For indeterminate greenhouse tomato cultivars, this fruit growth duration value corresponds to that for individual fruits from anthesis to handharvest ripe maturity for that specific cohort. For indeterminate greenhouse cultivars, flower clusters continue to be formed and mature for many months after the first fruits are being harvested. However, for semideterminate fieldgrown cultivars that are harvested within a period of 1 to 2 weeks, the individual fruit growth period from anthesis to maturity (greenbreaker) for the first larger fruits corresponds within a few days to the whole crop period from first fruit set to total crop maturity. For this late reproductive phase (fruit development rate and progression to maturity), Adams et al. (2001) found values of $5.7{ }^{\circ} \mathrm{C}$ for base and $22{ }^{\circ} \mathrm{C}$ for Topt1. De Koning (1994) proposed
$4{ }^{\circ} \mathrm{C}$ for base temperature, $\approx 21{ }^{\circ} \mathrm{C}$ for optimum, and presented no data for $\mathrm{Topt}_{2}$ or the maximum value. Aikman (1996) proposed that the time from anthesis to maturity for tomato is 806 degree-days using a base temperature equal to $4.75^{\circ} \mathrm{C}$. Using the $4{ }^{\circ} \mathrm{C}$ of De Koning (1994), this time translates to 940 degree-days, whereas Scholberg et al. (1997) calculated 722 degree-days using a base temperature equal to $10{ }^{\circ} \mathrm{C}$. Beyond these differences in computing thermal units, it is also likely the cultivars may differ in the duration from anthesis to harvest maturity.

According to De Koning (2000), temperature appears to be a principal factor determining the duration of the tomato fruit growth period. His results showed this period to be $73 \mathrm{~d}$ at $17{ }^{\circ} \mathrm{C}$ and $42 \mathrm{~d}$ at $26^{\circ} \mathrm{C}$. Similar results were found by Rylsky (1979). Verkerk (1955) found that the time interval from anthesis to harvest was $90 \mathrm{~d}$ at $13{ }^{\circ} \mathrm{C}, 53 \mathrm{~d}$ at $19{ }^{\circ} \mathrm{C}$, and $40 \mathrm{~d}$ at $26^{\circ} \mathrm{C}$. In his experiment, De Koning divided the growth period into five phases and found different responses to temperature depending on fruit age. High temperature shortened the growth period during two phases, first during the young developmental phrase and again close to maturity when temperature had a great impact on days to harvest. The middle phase of fruit growth was less sensitive to temperature. Adams et al. (2001) and Adams and Valdez (2002) found that when tomato plants were grown at $14,18,22$, and $26^{\circ} \mathrm{C}$, fruits ripened after $95,65,46$, and $42 \mathrm{~d}$, respectively. They found that fruits were more sensitive to elevated temperature in their later stages of maturation. Their results showed a reduction in days to harvest of 8.7 to $11.2 \mathrm{~d}$ when temperatures were increased from 18 to $25^{\circ} \mathrm{C}$ for a 3 -week period.

In summary, for rate of development from anthesis to maturity and rate of fruit development/maturation, we used cardinal temperature values of $5.2,26,28$, and $48{ }^{\circ} \mathrm{C}$ for base, Topt ${ }_{1}, \mathrm{Topt}_{2}$, and Tmax, respectively (Table 1). In absence of data to support the Tmax value, we used a high value of $48^{\circ} \mathrm{C}$ to ensure rapid progression at high temperature.

Fruit set and pollination. The temperature range for fruit setting in tomato is narrow and especially the night temperature is critical. The optimal range reported for fruit setting in tomato is reported to be 15 to $20^{\circ} \mathrm{C}$ (Went, 1945 ) and 18 to $20{ }^{\circ} \mathrm{C}$ (De Koning, 1994). Fruit set is low at both low and excessively high temperatures. Hot conditions may result in cone splitting, stigma exertion, and pollen sterility, and maximal day temperature in excess of $32{ }^{\circ} \mathrm{C}$ and/or minimal night temperature above $21^{\circ} \mathrm{C}$ will greatly reduce fruit set (Benedictos and Yavari, 2000; Moore and Thomas, 1952). These authors did not find cultivar differences in the tomato species they evaluated with respect to flower abortion at high temperatures $\left(37 / 21{ }^{\circ} \mathrm{C}\right.$ day/night). However, differences may occur between heat-sensitive and heat-tolerant tomato cultivars (Lohar and Peat, 1998). Because flower fertility is greatly decreased by these excessively high temperatures, the result will be fewer fruits set and reduced yield. The simulation of this effect by tomato models has been poor in general as also noted by Marcelis et al. (2009). The CROPGROTomato species file includes a temperature function for fruit addition (rate) that mimics elevated temperature effects on flower fertility. The cardinal temperatures of $7{ }^{\circ} \mathrm{C}(\mathrm{Tb})$, $22{ }^{\circ} \mathrm{C}\left(\mathrm{Topt}_{1}\right)$, and $26^{\circ} \mathrm{C}\left(\mathrm{Topt}_{2}\right)$ proposed by Adams et al. (2001) for progression to anthesis appear to also be valid for fruit addition and pollination except their experiments did not explore values for ceiling failure temperature. For fruit pollination, the value for ceiling failure temperature is critical because the fertility of tomato flowers is compromised at high temperature. According to Benedictos and Yavari (2000) and Moore and Thomas (1952), fruit set and pollination will fail at daytime temperatures above $32{ }^{\circ} \mathrm{C}$ or at night temperatures above $2{ }^{\circ} \mathrm{C}$. Heuvelink (2005) reported that flower fertilization in tomatoes is greatly reduced at temperatures outside the 5 to $37^{\circ} \mathrm{C}$ range and that the growth rate of pollen tube is adequate within this temperature range. According to Atherton and Harris (1986), fruit pollination will fail above $40{ }^{\circ} \mathrm{C}$ and the most critical stage appears to be meiosis, which occurs $\approx 9 \mathrm{~d}$ before anthesis. The optimal temperature for pollination according to those authors is between 17 and $24{ }^{\circ} \mathrm{C}$. They proposed a base temperature of $5{ }^{\circ} \mathrm{C}$. However, because the Adams et al. (2001) experiments were carried out in controlled temperature environments, we will adopt values from Adams et al. for Tb, Topt ${ }_{1}$, and Topt ${ }_{2}$ with slight modifications slanted toward information provided by other authors with the inclusion of ceiling temperature effects on fruit set. Therefore, we propose cardinal temperature values of $6,21,26$, and $33{ }^{\circ} \mathrm{C}$ for base, $\mathrm{Topt}_{1}, \mathrm{Topt}_{2}$, and Tmax, respectively, for fruit set in the modified CROPGRO-tomato input file (Table 1). In addition, the CROPGROTomato species file includes a function that reduces the partitioning limit to fruit growth (XFRT) if temperature is too high (partitioning to fruit is reduced above $28{ }^{\circ} \mathrm{C}$ and falls to zero at $34{ }^{\circ} \mathrm{C}$ ) and this function is an additional contributor to elevated temperature effects on fruit addition in the model (Boote and Scholberg, 2006).

Linking flowering, fruit set, and fruit growth with individual fruit cohorts in CROPGRO. Flowering, fruit set, and fruit addition in the CROPGRO model are processes based on a cohort structure, whereby successive flowers are added daily, which after a very short lag become fertilized fruits that grow slowly at first and then begin a phase of rapid growth (see Boote et al., 1998, for more detail on this). The addition of successive flowers, addition of successive fruits (translation from flower to fruit), and the growth of individual fruits depend on daily assimilate supply as well as these cardinal temperatures affecting fruit set and fruit growth rate. Thus, non-optimum temperatures, beyond those affecting photosynthesis, will reduce fruit set and individual fruit growth on each day. Fruit growth has first priority for assimilate up to the genetic partitioning limit of XFRUIT; 
Table 3. Cultivar coefficients for CROPGRO-Tomato model, default, and calibrated values for cultivars Sunny, Agriset 761, Florida-47, and Solarset after updating the cardinal temperatures in SPE file.

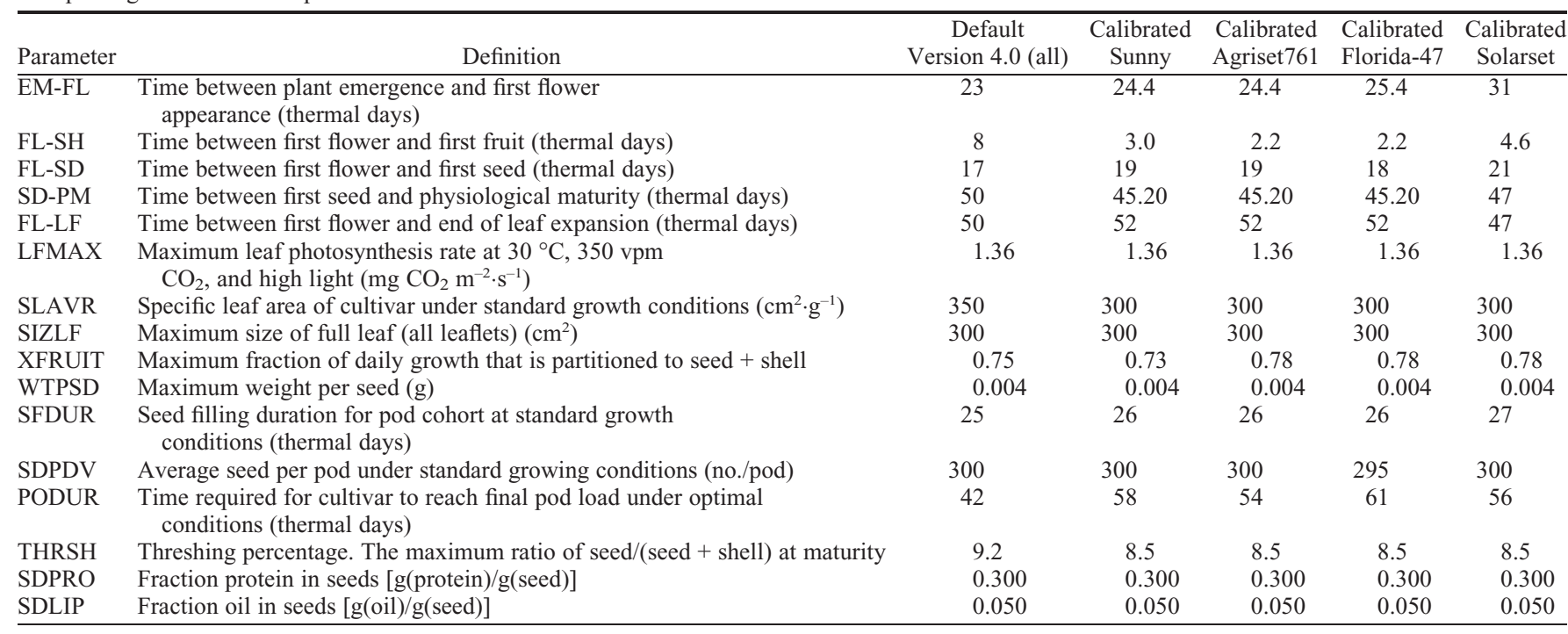

Table 4. Modified parameters in ecotype file, default Version 4.0 values, and calibrated values.

\begin{tabular}{lcc}
\hline Parameter & Default values & Calibrated values \\
\hline Time between planting and emergence PL-EM (Td) & 5 & 6 \\
Time between emergence and first true leaf EM-V1 (Td) & 20 & 22 \\
Time required for growth of individual fruit LNGSH (Td) & 35 & 39 \\
Time between first flower and last leaf in main stem FL-VS (Td) & 18 & 24.5 \\
PMO6, if PM06 is 0.0, there is no slow growth phase; if & 0.0 & 0.55 \\
$\quad$ PMO6 greater than 0.0, there is a slow growth phase & & 0.52 \\
Rate of leaf appearance on main stem, TRIFL & & 0.45 \\
\hline
\end{tabular}

$\mathrm{Td}=$ thermal days.

thus, a carrying capacity of numbers of fruits or "fruit load" will be reached. Moreover, this partitioning limit to fruit is reduced by heat stress as indicated previously. First-set fruits will be larger than later ones, but after this carrying capacity is reached and numbers are "set," all fruits share equally if assimilate is limiting.

Fruit growth rate. Temperature is the climatic factor that most affects fruit rate growth in tomato (Pearce et al., 1993; Walker and Ho, 1977). Hurd and Graves (1984) suggested a $\mathrm{Q}_{10}$ value of 1.7 for tomato fruit growth and $\mathrm{Q}_{10}$ of 2.0 for fruit maturation (Hurd and Graves, 1984). For fruit growth rate (DM and water accumulation), Rylsky (1979) found an optimum equal to $26{ }^{\circ} \mathrm{C}$, whereas Adams et al. (2001) found a regimen of 25/ $25{ }^{\circ} \mathrm{C}$ (day/night) to be optimum for fruit growth rate. De Koning (1994) proposed $10{ }^{\circ} \mathrm{C}$ for base temperature. No authors reported on the ceiling temperature for the fruit growth rate because such values are difficult to obtain. In the absence of data on ceiling temperature effects on fruit growth, the $\operatorname{Tmax}\left(32^{\circ} \mathrm{C}\right)$ for fruit growth rate was assumed close to that of fruit set $\left(33{ }^{\circ} \mathrm{C}\right)$. In addition, we selected $\mathrm{a} \mathrm{T}_{\mathrm{b}}$ of $6{ }^{\circ} \mathrm{C}$ to be consistent within $1{ }^{\circ} \mathrm{C}$ of the $\mathrm{T}_{\mathrm{b}}$ values used for vegetative, reproductive, and fruit set processes. From all these sources, we adopted $6,22,25$, and $32{ }^{\circ} \mathrm{C}$ for $\mathrm{T}_{\mathrm{b}}$, Topt $_{1}$, $\mathrm{Topt}_{2}$, and Tmax, respectively, as cardinal temperatures for fruit (and seed) growth rate for the modified CROPGRO tomato input file (Table 1). Individual fruits grow at a daily rate that depends on the growth temperature as well as assimilate supply, and individual fruit growth is independent of whole plant developmental stages.

Photosynthesis response to temperature. Many plants show an optimum temperature for photosynthesis close to their normal growth temperature (Lambers et al., 1998). The optimum temperature for tomato plant growth ranges between 22 and $30^{\circ} \mathrm{C}$ (Ogweno et al., 2009). According to Heuvelink and Dorais (2005), tomato single-leaf photosynthesis has an optimum temperature between 20 and $30^{\circ} \mathrm{C}$ at ambient $\mathrm{CO}_{2}$ and between 25 and $30{ }^{\circ} \mathrm{C}$ when $\mathrm{CO}_{2}$ concentration is high. In an experiment conducted by Xu et al. (1999) net photosynthesis increased steadily as the leaf temperature increased from 18 to $23{ }^{\circ} \mathrm{C}$ and then decreased steadily from 23 to $38{ }^{\circ} \mathrm{C}$. Dark respiration increased in an exponential manner (by a factor of 10) as the leaf temperature increased from 18 to $38^{\circ} \mathrm{C}$. In a study conducted by Ogweno et al. (2009), detached tomato leaves were exposed to 15,25 , and $35^{\circ} \mathrm{C}$ for $5 \mathrm{~d}$. Leaves at $15^{\circ} \mathrm{C}$ exhibited similar photosynthetic rate as those at $25^{\circ} \mathrm{C}$, whereas leaves at $35{ }^{\circ} \mathrm{C}$ had significantly lower net $\mathrm{CO}_{2}$ assimilation rates (similar to reports of De Koning, 1994). Hu et al. (2006) demonstrated that the decreased photosynthetic rate at $35^{\circ} \mathrm{C}$ was not related to stomata function but was related to impaired photosynthetic apparatus. Optimal temperature for photosynthesis of tomato at $350 \mathrm{ppm} \mathrm{CO}_{2}$ was reportedly $22{ }^{\circ} \mathrm{C}$ (Acock, 1991; Cannell and
Thornley, 1998) and $30{ }^{\circ} \mathrm{C}$ (Heuvelink and Dorais, 2005). Low temperatures of 4 and $6{ }^{\circ} \mathrm{C}$ were found to dramatically reduce photosynthesis of tomato plants (Byrd et al., 1995), whereas at $1{ }^{\circ} \mathrm{C}$, photosynthesis of tomato leaves ceased (Martin et al., 1981). The $\mathrm{T}_{\mathrm{b}}$, $\mathrm{Topt}_{1}, \mathrm{Topt}_{2}$, and Tmax, respectively, for light-saturated, $\mathrm{CO}_{2}$-saturated leaf photosynthesis were changed from $5,26.5,34$, and $48{ }^{\circ} \mathrm{C}$ for the default leaf level (L version) to $6,28,34$, and $48^{\circ} \mathrm{C}$ in the modified model, in part from field calibration but considering these somewhat variable reports.

There is also a minimum night temperature effect in the model that reduces the next day's leaf photosynthesis, which concurs with reported reductions in photosynthesis of tomato when the minimum temperature (Tmin; night temperature) is below $10^{\circ} \mathrm{C}$ (Byrd et al., 1995). For the modified model, an asymptotic function reduces photosynthesis beginning at $\mathrm{Tmin}$ of $15^{\circ} \mathrm{C}$, going to zero rate at Tmin of $-2{ }^{\circ} \mathrm{C}$. The respective values for the default version were 5 and $0{ }^{\circ} \mathrm{C}$ with no justification. The justifications for modifying these two functions are the literature values reported previously along with calibration to field growth analyses. In particular, an increase in $\mathrm{T}_{\mathrm{b}}$ from 5 to $6{ }^{\circ} \mathrm{C}$ and increase in $\mathrm{Topt}_{1}$ to $28^{\circ} \mathrm{C}$ were found necessary for accurately predicting biomass accumulation in the contrasting cooler seasons or times of year (Bradenton) vs. the warmer seasons in Quincy and Gainesville. Likewise, the greater reduction caused by the new Tmin values was needed for the same reason to reduce DM accumulation in the cooler time of year, especially at Bradenton, and to be consistent with literature confirming a night temperature effect on photosynthesis.

Stem and leaf growth. The internode length growth shows a marked linear response to temperature, according to Langton and Cockshull (1997) who exposed tomato plants in growth chambers to 24 factorial combinations of day (DT) and night (NT) temperatures ranging from 12 to $32{ }^{\circ} \mathrm{C}$. Their experimental data for tomato growing over a $10-\mathrm{d}$ period at 
$16,20,24$, and $28^{\circ} \mathrm{C}$ average (over NT and DT) air temperatures showed that the corresponding lengths reached by the internodes were $12,18,27$, and $30 \mathrm{~mm}$, respectively. Their experiments showed increased extension growth with increase in DT and indicated that the optimum DT for extension growth is close to $28{ }^{\circ} \mathrm{C}$. In the CROPGRO model (default and modified input parameter files), the $\mathrm{Topt}_{1}$ for stem elongation and leaf expansion (specific leaf area) is $26{ }^{\circ} \mathrm{C}$ (close to Langton and Cockshull, 1997). There is no true $\mathrm{T}_{\mathrm{b}}$ in the model for this, but the relative expansion declines to 0.4 at $11^{\circ} \mathrm{C}$ and does not appear to go below 0.4 .

With the goal of improving temperaturedependent parameters in the CROPGROTomato model and after a literature search of cardinal temperatures for the species, the values published by Adams et al. (2001) were considered the most valuable and most reliable and were used because their study was carried out under precisely controlled temperature environments. Therefore, the adaptation of temperature-specific input parameters that are used for model simulation described in the next section are based mainly on the data reported by Adams et al. (2001), although the work of other authors is also considered for particular values or as substantiating information.

\section{Materials and Methods}

Evaluating modified temperature response functions in CROPGROTomato

Model description. The CROPGRO model used in this study is part of the DSSAT V4.0 software. A more complete model description can be found in the software documentation as well as in articles published by Boote et al. (1998) and Jones et al. (2003). The CROPGRO model simulates development based on multiple phases from emergence to harvest. Phenological development and growth processes such as leaf expansion and fruit growth depend on cardinal temperatures (Boote et al., 1998). Leaf area expansion depends on the new leaf mass produced and specific leaf area, which is influenced by light, temperature, root $\mathrm{N}$ uptake, and plant water status. The photosynthesis input to carbon balance begins as a function of light intercepted by the hedgerow canopy with leaf photosynthesis scaled up to canopy assimilation (Boote and Pickering, 1994). The daily growth of tissues results from the gain of photoassimilates through photosynthesis minus growth and maintenance respiration losses. The allocation of assimilates among vegetative organs is driven by partitioning coefficients, but fruits, once added, are explicit sinks that have first priority for using photoassimilates for new growth. Although considered semideterminate, the fresh-market tomato cultivars grown under field conditions exhibit low partitioning to vegetative sinks after the fruits begin their rapid growth phase. Thus, semideterminacy is simulated because the partitioning of assimilates to the reproductive sinks during the reproductive phase effectively causes leaf, stem, and root growth to end to the limits of (1XFRUIT), where XFRUIT is a parameter that determines the fraction of the available dry matter allocated to fruits (Boote and Scholberg, 2006). Submodels for $\mathrm{N}$ and water balance as well as pest damage coupling simulations are also available and can be switched on or off according to specific applications. The model requires three types of genetics-related files: species, ecotype, and cultivar files. The species file accounts for the sensitivity of crop processes to environmental factors such as temperature, solar radiation, $\mathrm{CO}_{2}$, and photoperiod.
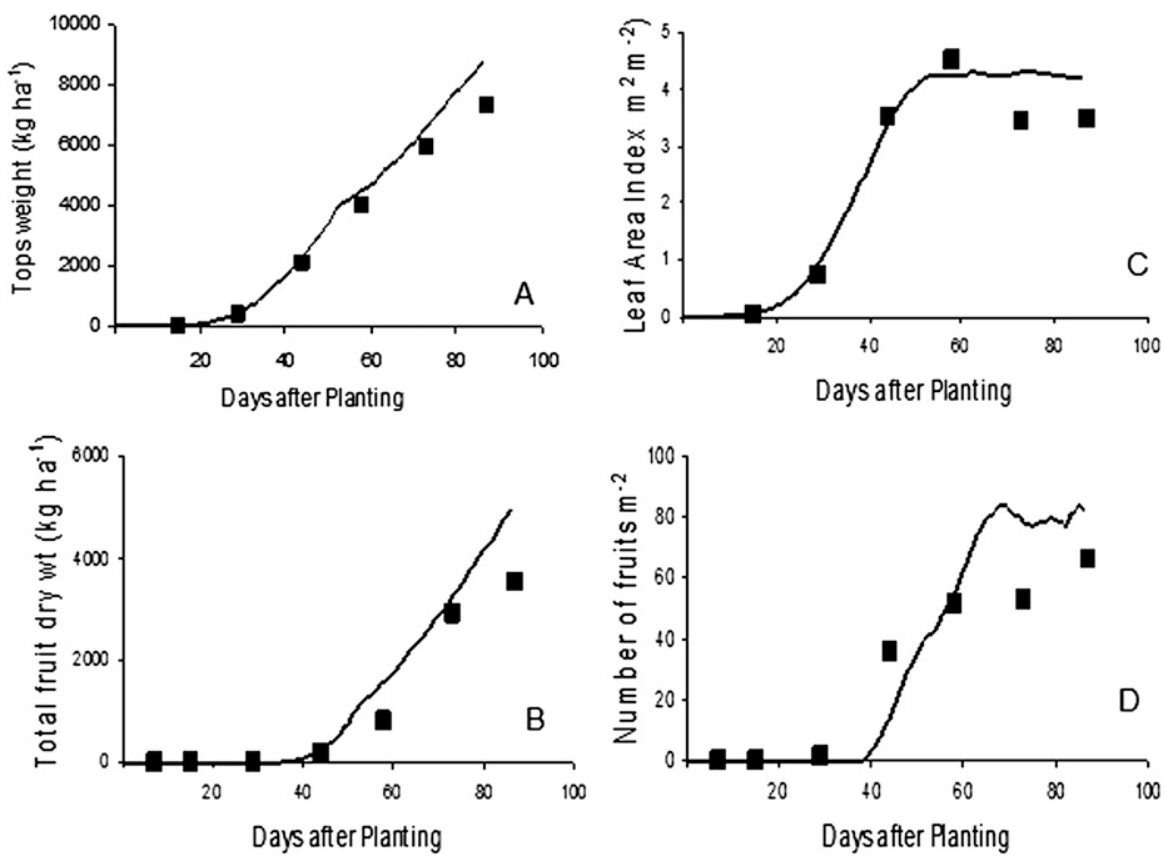

Fig. 1. Simulated (-) and observed (-) data of 'Sunny' tomato grown at Bradenton, FL, during spring of 1991. (A) Total top dry weight, (B) total fruit dry weight, (C) leaf area index, and (D) fruit number per $\mathrm{m}^{2}$.
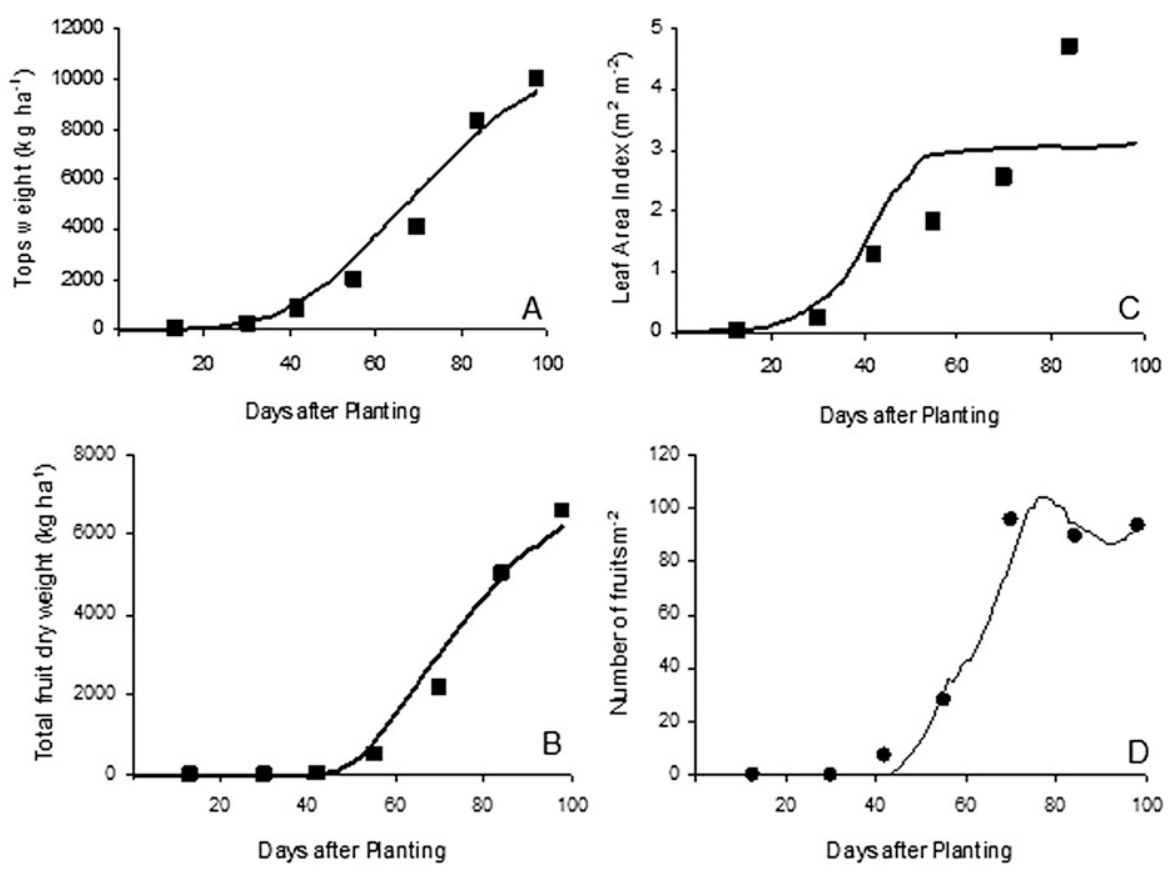

Fig. 2. Simulated (-) and observed (匚) data of 'Sunny' tomato grown at Bradenton, FL, during spring of 1992 (A) Total top dry weight, (B) Total fruit dry weight, (C) leaf area index, and (D) fruit number per $\mathrm{m}^{2}$. 
and plant processes are different from the values used by Scholberg et al. (1997), which are used in the CROPGRO-Tomato model (Version 4.0). Therefore, temperature-based functions were modified as discussed previously and the model was recalibrated, leading to a comparison of model performance of both the original and modified model versions.

Coefficients for life cycle were adjusted to account for effects of the new cardinal temperature parameters by comparison with the dates for the occurrence of first flowering, first fruit, and maturity observed during experiments carried out in Florida in 2006 and 2007. An additional objective in our calibration process was to preserve the same calendar day occurrences of phenological events as the prior experiments (1991 to 1996), because although phenology data were not available for those experiments, the model had been calibrated by Scholberg et al. (1997) with field data on DM production and yield under optimum irrigation, fertilization, and pest management so we assumed that prior phase durations were close to correct values. Genetic coefficients (EM-FL, FL-SH, FL-SD, SD-PM, FL-LF, XFRUIT, SFDUR, SDPDV, and PODUR) shown in Table 3 were calibrated for each of four different fresh-market tomato cultivars, although differences among cultivars were relatively few and small.

Parameters affecting leaf growth, DM production, and DM partitioning from transplanting to harvest were then calibrated against the observed data. Quality of dynamic simulation of leaf area index, aboveground biomass, fruit yield, and fruit number was evaluated by comparing the RMSE and the Willmott d index statistics for simulations using default vs. modified genetic parameters.

Field data used for model evaluation. The growth data for evaluation consisted of a series of 10 experiments conducted between 1991 and 2007 at three locations in Florida: Bradenton, Gainesville, and Quincy. Two experiments in Bradenton were conducted by Brian McNeal (University of Florida, Soil and Water Science Department) from 1991 to 1992 and are described in Scholberg et al. (1997, 2000a, 2000b). The treatments selected for evaluation were well-irrigated and well-fertilized, and, therefore, no water or $\mathrm{N}$ stress was present. The soil at Bradenton was Eaugallie fine sand. The data sets for Bradenton 1994 and 1995, Gainesville 1996, and Quincy 1995 were derived from field experiments conducted by Scholberg using irrigated tomatoes. Excluding the Quincy studies, all experiments were carried out during the spring season. For Quincy, one data set corresponded to the spring season and the other to the fall season. The Gainesville 2006 and 2007 data set was obtained from a well-fertilized and well-irrigated tomato crop grown in the field under plastic mulch in the spring of both years (Rybak, 2009). For Gainesville in 1996, the soil was a fine sandy soil of the Millhopper series. For Gainesville in 2006 and 2007, the soil is classified as Candler fine sand (Buster, 1979). The Quincy soils belonged to the Orangeburg series. The treatment was dripirrigated, and the $\mathrm{N}$ application rate was 330 $\mathrm{kg} \cdot \mathrm{ha}^{-1}$ at Gainesville, $180 \mathrm{~kg} \cdot \mathrm{ha}^{-1}$ at Quincy (spring), and $200 \mathrm{~kg} \cdot \mathrm{ha}^{-1}$ at Quincy (fall). For the simulations, the irrigation and $\mathrm{N}$ rates were not used as model inputs because the $\mathrm{N}$ and water balance were turned off for all simulations so potential growth was simulated.

The cultivars were Sunny (Asgrow, Kalamazoo, MI) for Bradenton, Agriset 761 (Petoseed, Ventura, CA) for Spring 1995 in Quincy and Spring 1996 in Gainesville, Solarset (Univ. of Florida, Gainesville, FL) for Fall 1995 in Quincy, and Florida 47 (Seminis-Monsanto, St. Louis, MO) for Gainesville in 2006 and 2007.
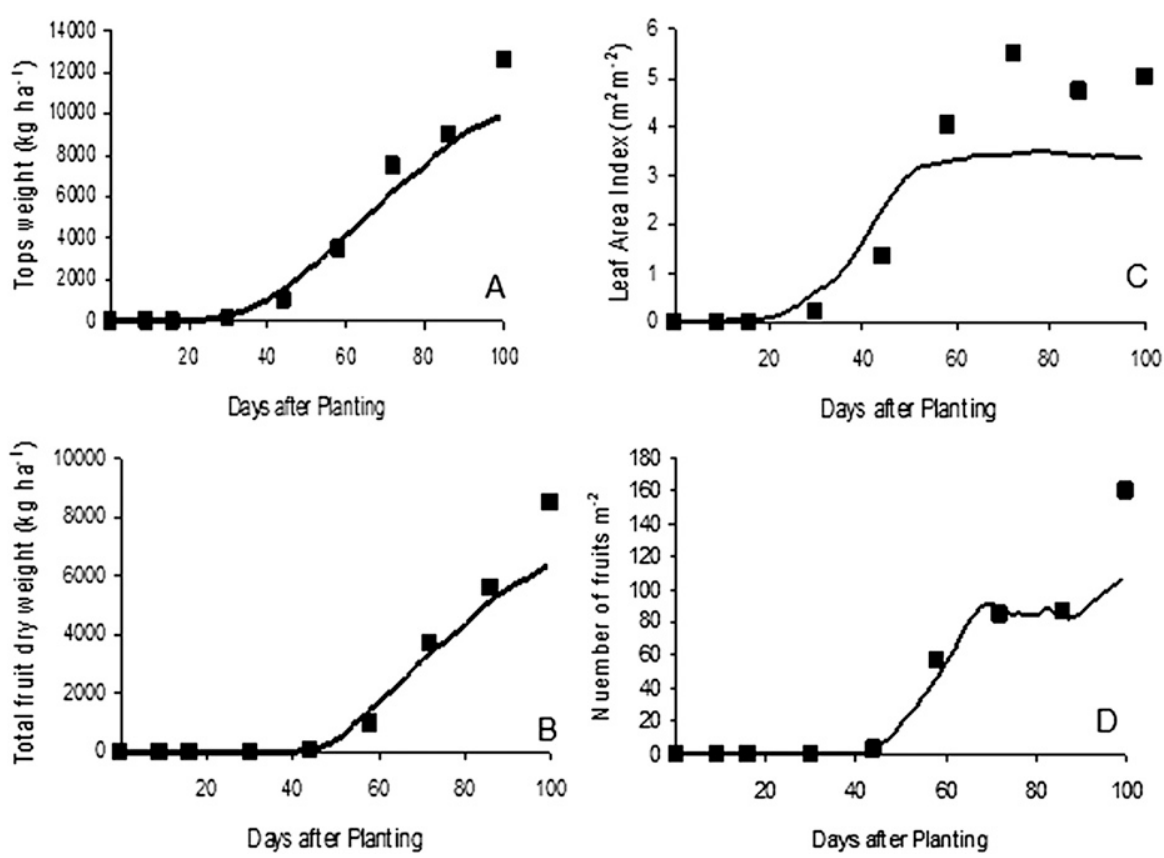

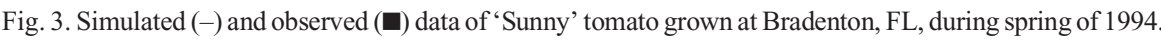
(A) Total top dry weight, (B) total fruit dry weight, (C) leaf area index, and (D) fruit number per $\mathrm{m}^{2}$.
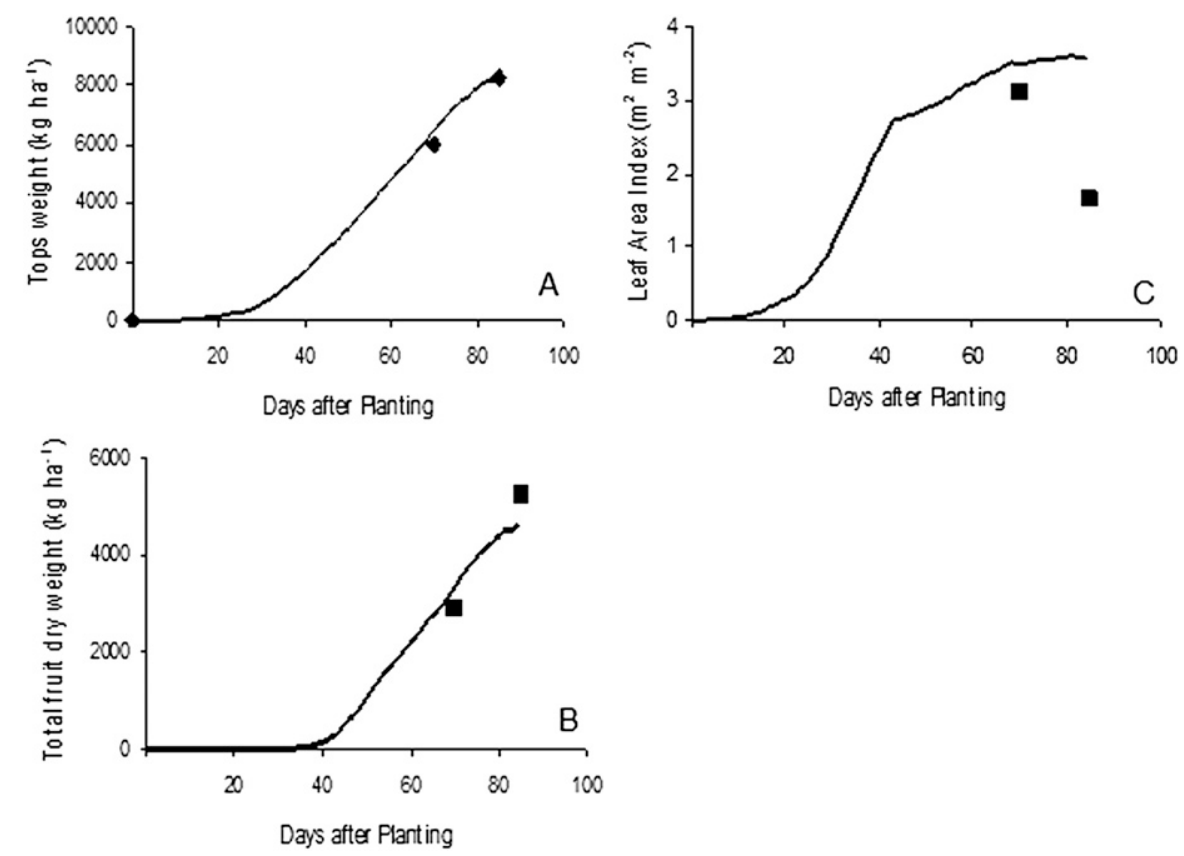

Fig. 4. Simulated (-) and observed (ם) data of 'Sunny' tomato grown at Bradenton, FL, during spring of 1995. (A) Total top dry weight, (B) total fruit dry weight, and (C) leaf area index. 
rate and considerably shortened the life phase durations as expected (data not shown). Because of lower $\mathrm{T}_{\mathrm{b}}$, the cultivar phase durations were recalibrated to larger values to attain the same phenology dates simulated with the higher $T_{b}$ of Scholberg et al. (1997). In addition, the age of the plants at the time of transplanting was adjusted for each experiment (Table 2). The simulation control file requires a transplant age. For the modified model, the plants were generally 1 to $3 \mathrm{~d}$ younger at the time of transplanting than used in the default version, again caused by the new base temperatures. The actual age of plants for those experiments was not available and therefore the criterion for this adjustment was a better phase duration adjustment when cardinal temperatures were modified considering that plant age at transplanting usually ranges between 3 and 4 weeks in Florida production systems.

Cultivar coefficient calibration was performed to adjust the life cycle after entering the new cardinal temperatures in the species file (Table 1) and results are shown in Table 3. The main changes in the cultivar file were the coefficients that determine the phase durations. First, the timing of flower and fruit appearance was adjusted. The cultivar coefficient EM-FL (days between plant emergence and flowering) was calibrated to a larger value to predict the anthesis date. The calibration of time from flowering to first fruit, FL-SH, required a new approach that is described in the following paragraph. The next sequential phase in the life cycle, the cultivar coefficient FL-SD (time from flower to first seed), was increased by $\approx 2$ thermal days for cultivars Sunny and Agriset 761, by 1 thermal day for cultivar Florida 47, and by 4 thermal days in case of the cultivar Solarset. To improve the growth of fruits and seeds, the coefficients PODUR (duration of pod addition) and SFDUR (duration of seed filling) required calibration. Averaging over cultivars, the PODUR was increased $\approx 8$ thermal days, and SFDUR was increased $\approx 1$ thermal day. The phase duration coefficients described so far represent the phase durations that would occur under optimum temperature conditions (between Topt $_{1}$ and Topt ${ }_{2}$ ), but actual calendar days for a phrase could be longer at nonoptimum temperature. In addition, to give more priority to shell (fruit) growth over seed growth, the threshing percentage was slightly decreased from 9.2 to 8.5. The coefficient SLAVAR (specific leaf area under standard growing conditions) was decreased from 350 to $300 \mathrm{~cm}^{2} \cdot \mathrm{g}^{-1}$ for all cultivars.

Individual tomato fruit ovules (small fruits) are already present at the time the subtending flower opens; thus, there is already a fruit present at flowering (thus the requirement for a very short thermal time for FL-SH, reduced from 8 to values ranging from 2.2 to 4.6 thermal days depending on the cultivar). More importantly, individual fruit growth after flower opening has an initial period of very slow growth, which lasts $\approx 2$ weeks after anthesis (Bohner and Bangerth, 1988; Gillaspy et al., 1993; Heuvelink, 2005; Mapelli et al., 1978; Varga and Bruinsma,
1986). This lag in fruit growth was not considered in the default version. For the modified model, we set a shorter lag (FL-SH) as well as a slow initial growth phase based on data on individual fruit growth (Rybak, 2009). For CROPGRO (already used for the peanut model), there is a PM06 coefficient that represents the fraction of time between beginning fruit growth to beginning seed growth during which the fruit grows at a slower rate (defined by SHLAG). For tomato, the
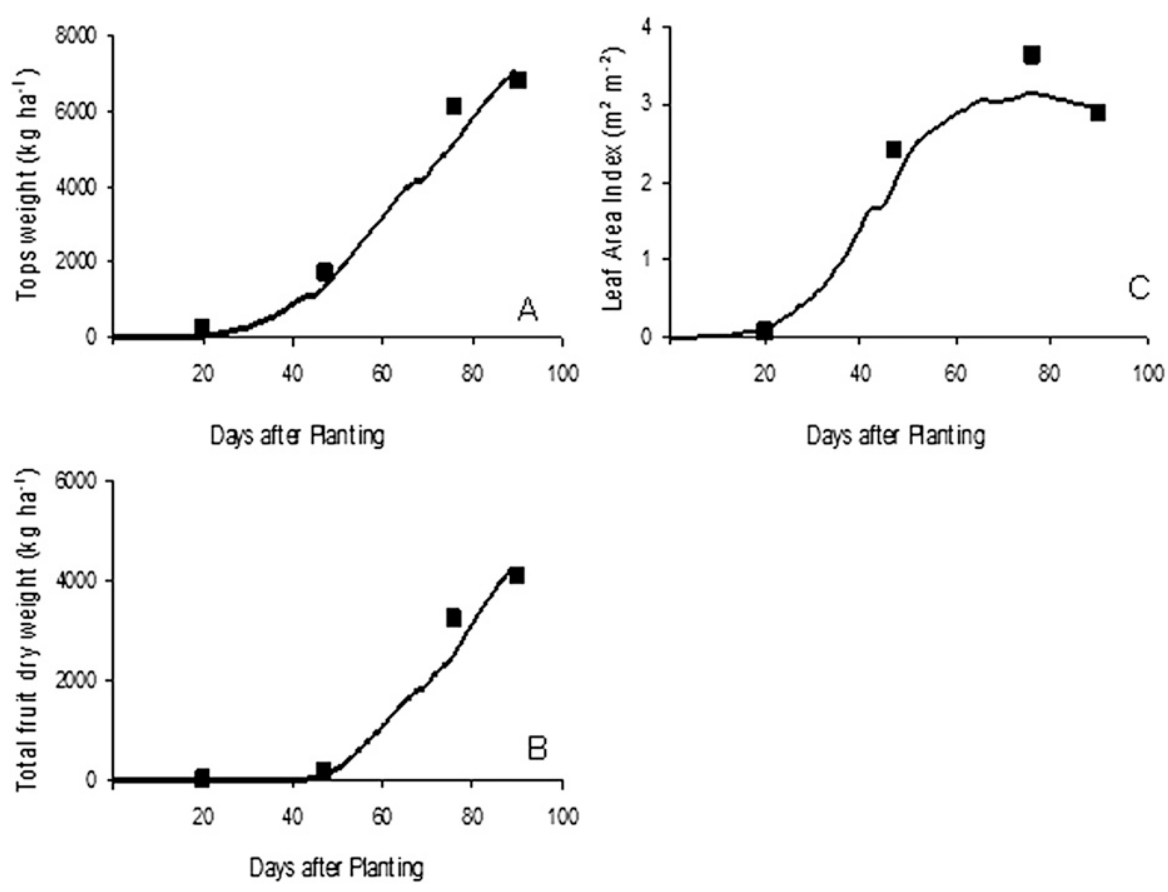

Fig. 5. Simulated (-) and observed (ם) data of 'Agriset 761' tomato grown at Quincy, FL, during spring of 1995. (A) Total top dry weight, (B) total fruit dry weight, and (C) leaf area index.
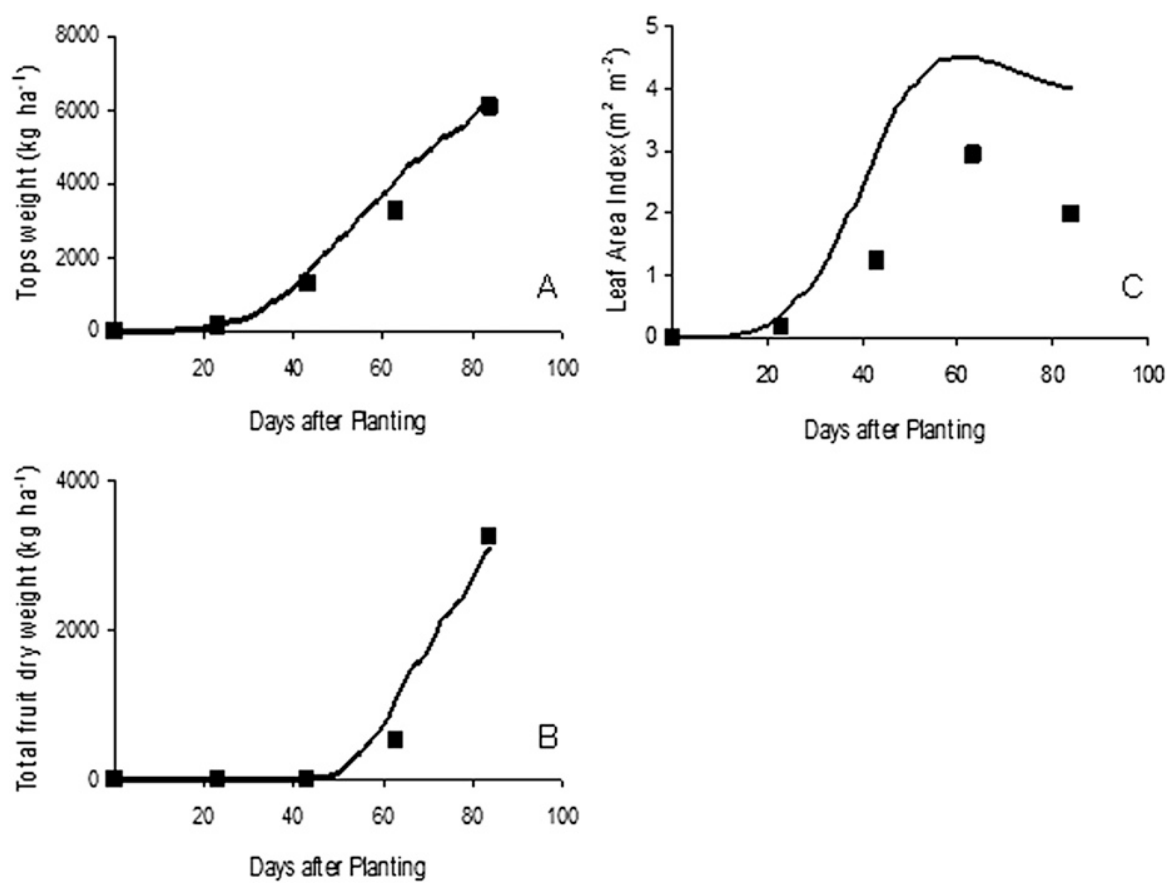

Fig. 6. Simulated (-) and observed (ם) data of 'Solarset' tomato grown at Quincy, FL, during fall of 1995. (A) Total top dry weight, (B) total fruit dry weight, and (C) leaf area index. 
tomato fruit growth after anthesis occurs at a rate that is $10 \%$ of the rate occurring during the rapid growth phase, which agrees with Dorais et al. (2001). Table 4 lists these ecotype parameters for PM06, SHLAG, and LNGSH.

For tomato, the parameter PMO6 was set to 0.55 (Rybak, 2009). This modification was needed to appropriately simulate the development and growth over time of three fruit cohorts whose development and growth began at different dates (separated by 1 week) based on the flower tagging dates (Rybak, 2009). Our experiments during 2007 indicated that first fruit (with small open flower) were set $28 \mathrm{~d}$ after transplanting. Therefore, our calibration process, in addition to the changes in cardinal temperatures, had to account for these observed fruit setting dates. Fruit set (small but slow-growing fruits) occurs within a few days $(\mathrm{FL}-\mathrm{SH} \approx 3)$ after flowering. The ability of the model to correctly predict the time for first fruit is important for our purposes of improving the model as described in this article as well as to mimic the fundamentals of individual fruit growth for tagged cohorts that will be explained in a future article.

Changing the cardinal temperatures also required recalibration of other parameters in the ecotype file (Table 4), primarily associated with an increase in the required thermal time to complete vegetative phases in the crop life cycle according to our observations. Furthermore, the maximum rate of leaf/truss appearance was slightly reduced from 0.52 in the default version to 0.45 .

After calibration, model-predicted dates for anthesis, first fruit, and physiological maturity more closely matched field observations. This also agrees with reports in the literature that indicated that first anthesis occurs 3 to 4 weeks after transplanting and that the whole life cycle from transplanting to harvest takes $\approx 90 \mathrm{~d}$ under moderately warm temperature. In addition, individual cohorts tagged at different dates during 2006 and 2007 seasons were adequately tracked by the model, which was useful for later single fruit growth studies that we performed with the model.

Aboveground biomass and fruit yield. The total aboveground biomass and fruit DM accumulation over time were well simulated using the modified parameters for all the experiments (Figs. 1A-B to 10A-B). On average, simulations using the modified parameters produced RMSE values that were $36 \%$ lower for both total biomass and fruit dry matter observations over time as compared with the default version (Table 5). Because the comparisons were made using time-series data, the Willmott $d$ index provided a better indication of model performance and/or improvement. Overall, the d index was higher for total dry weight and fruit dry weight using modified parameters. On average, this index for the modified version was 0.99 and 0.97 for total above biomass and fruit dry weight, respectively. The default version produced an average $\mathrm{d}$ value equal to 0.97 for total above biomass and 0.93 for total fruit weight.

Leaf area index. For most of the experiments, the progression of leaf growth was well
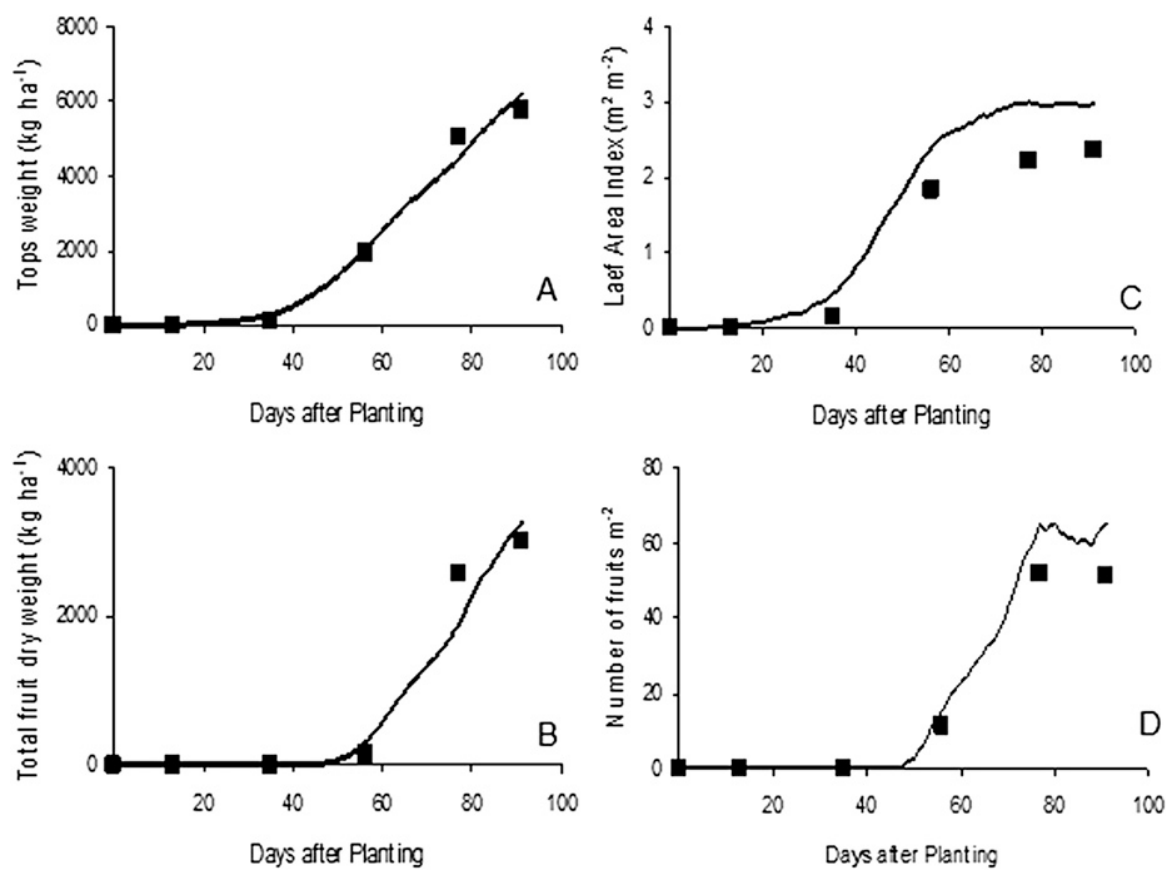

Fig. 7. Simulated (-) and observed ( $\mathbf{\square}$ ) data of 'Agriset 761' tomato grown at Gainesville, FL, during 1996. (A) Total top dry weight, (B) Total fruit dry weight, (C) Leaf Area Index, and (D) Fruit number per $\mathrm{m}^{2}$
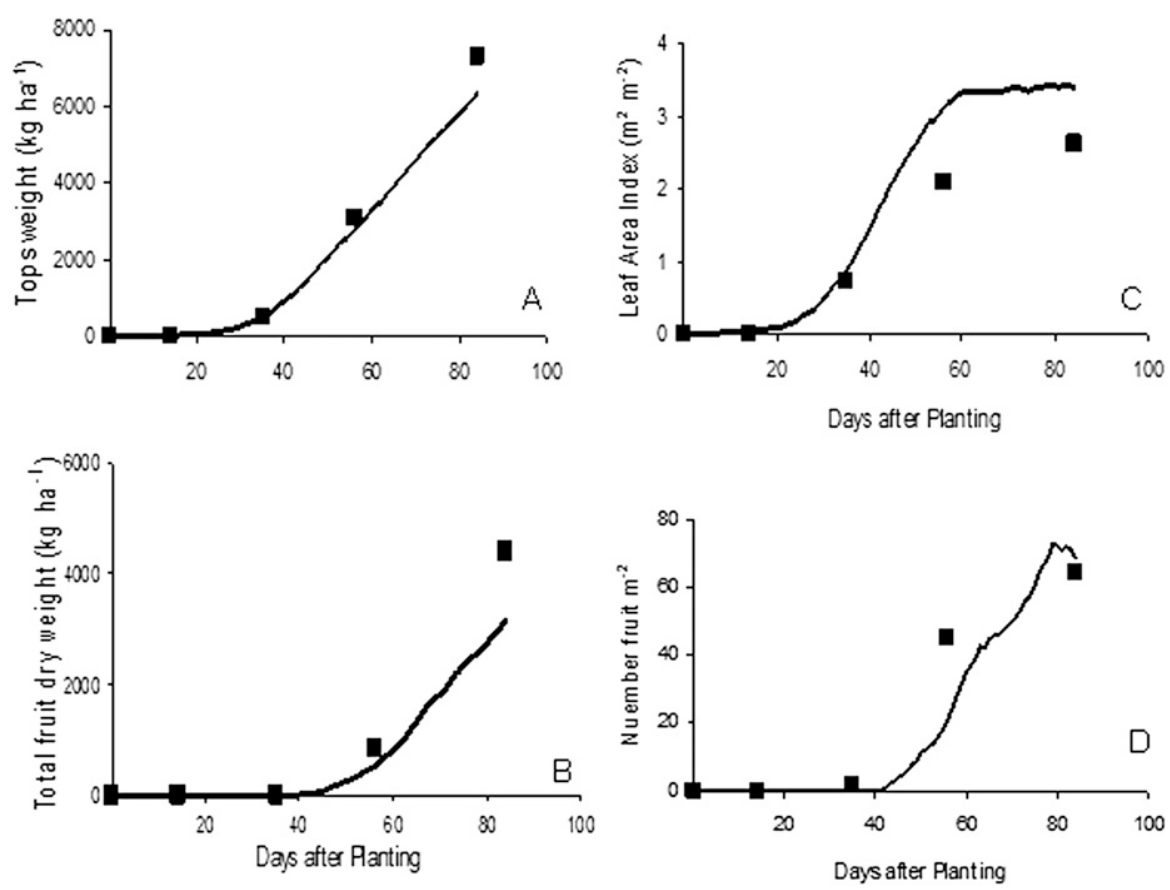

Fig. 8. Simulated (-) and observed ( $\square$ ) data of 'Agriset 761' tomato grown at Gainesville, FL, during 1996. (A) Total top dry weight, (B) total fruit dry weight, (C) leaf area index, and (D) fruit number per $\mathrm{m}^{2}$.

simulated by the modified model (Figs. $1 \mathrm{C}$ to 10C). In general, the modified parameters demonstrated better performance for simulating leaf area index (LAI) compared with the default version (statistics of time series data are shown in Table 5). Using the modified parameters the average RMSE for LAI over all the experiments was $44 \%$ lower than using default values. The Willmott $d$ index was higher using modified parameters than using the default ones. Nevertheless, there were some weak- nesses in LAI prediction: in several experiments, the maximum LAI was overestimated, and in other experiments, the LAI was underestimated. Because of these differences, it is difficult to obtain LAI simulations that satisfy the observations for all the experiments. Later in the season, the model was not able to reproduce accurately the decline in LAI associated with senescence and $\mathrm{N}$ remobilization, which appeared in some but not all seasons. This may be partially solved by "turning on" 

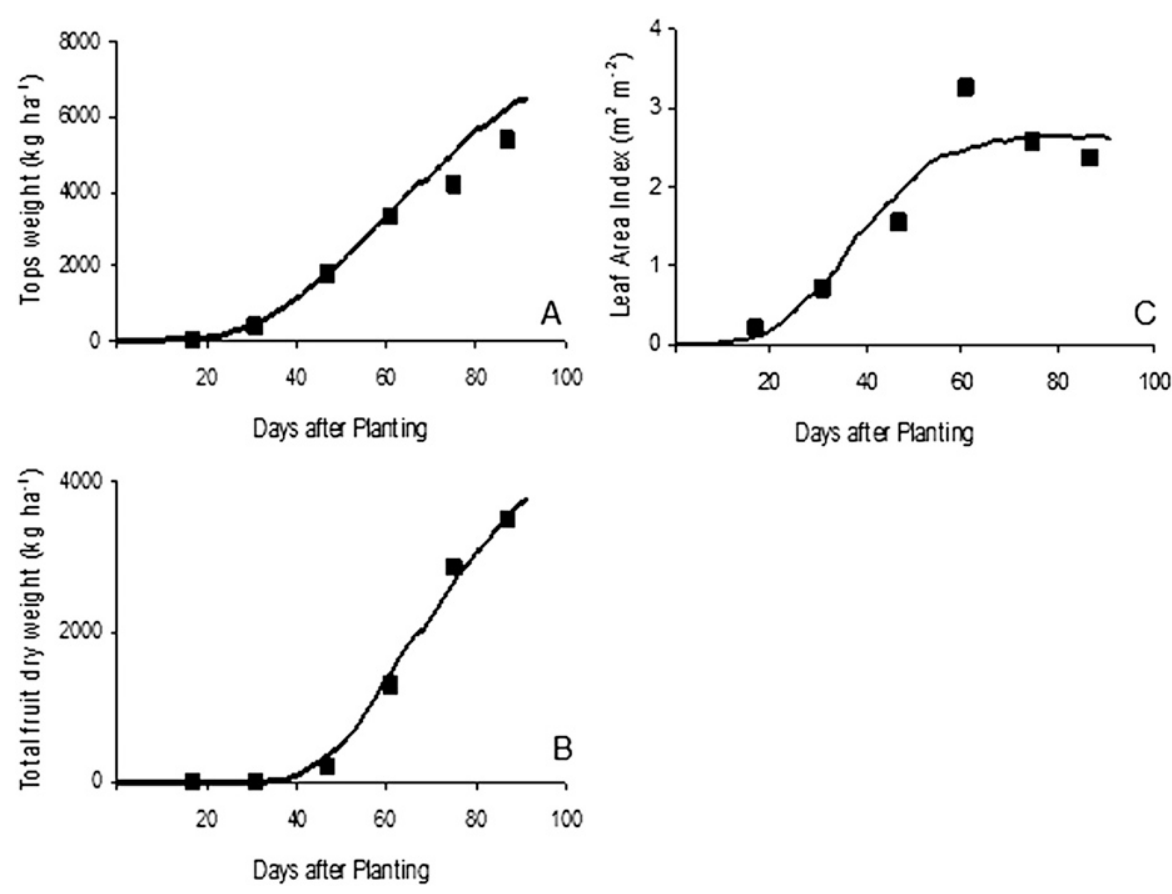

Fig. 9. Simulated (-) and observed (ם) data of 'Florida 47' tomato grown at Gainesville, FL, during 2006. (A) Total top dry weight, (B) total fruit dry weight, and (C) leaf area index.
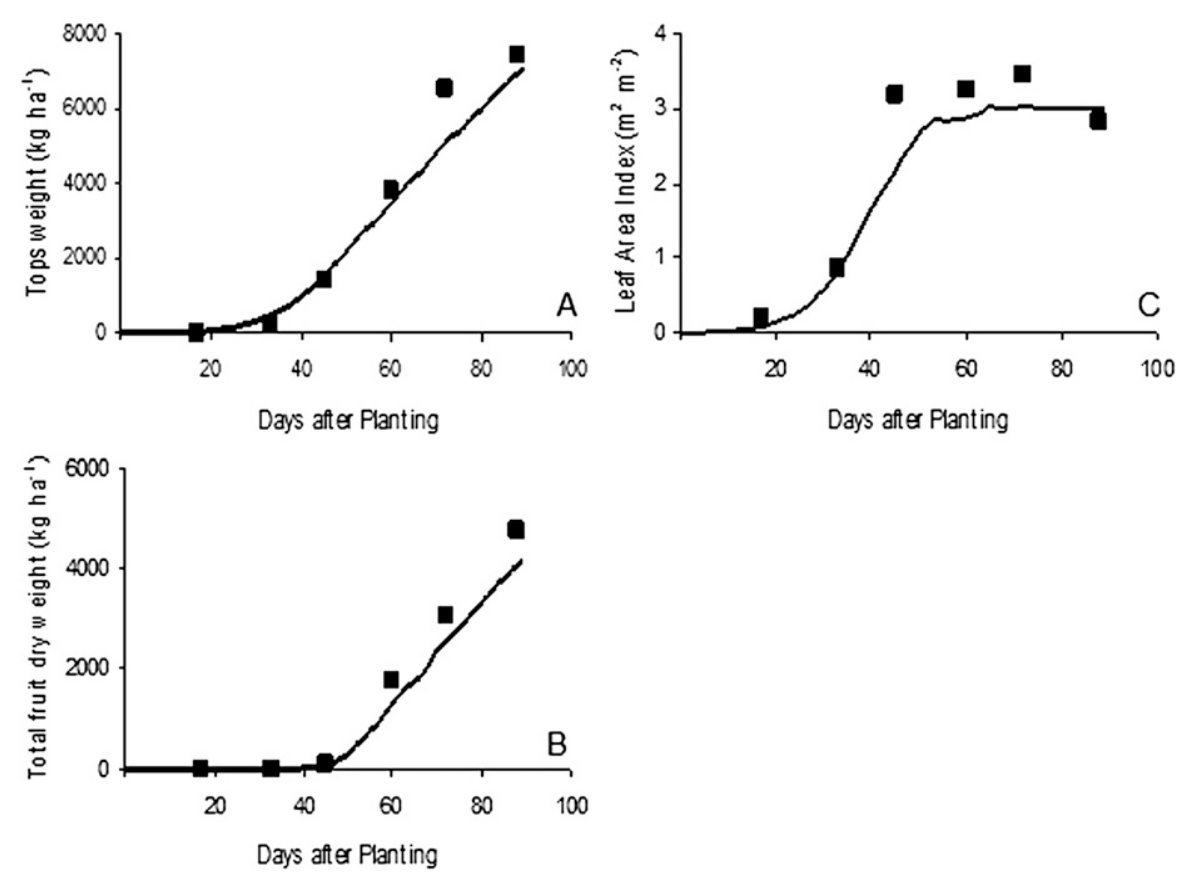

Fig. 10. Simulated (-) and observed (匹) data of 'Florida 47' tomato grown at Gainesville, FL, during 2007. (A) Total top dry weight, (B) total fruit dry weight, and (C) leaf area index.

the $\mathrm{N}$ balance of the model as well as by adjusting remobilization functions in the model such as the maximum rate of remobilization of protein (NMOBMX) from vegetative to reproductive tissues, which interacts with $\mathrm{N}$ nutrition, which we have assumed as unlimiting in these simulations. The $\mathrm{N}$ nutrition may not be unlimiting in reality, so we declined to try such modifications.

Simulations of stem and leaf weight were improved using the modified parameters for all cultivars, years, and sites (data not shown). The specific leaf area (SLA) was not well simulated by the model, regardless of the version used. In addition, the Willmott d values for SLA were low, indicating that the variability in the mean SLA throughout the season was not well captured by the model. Two possible explanations exist: 1) observed SLA can vary depending on inclusion or exclusion of midrib (because we do not know how data before 2006 were collected); and 2) the model SLA depends basically on radiation and temperature, but modeled SLA may fail to account sufficiently for ontogenetic changes and changes associated with $\mathrm{N}$ nutrition.

Fruit number. The fruit number over time was well simulated by the model when modified parameters were used (Figs. 1D to 8D). The default version produced poor simulation of fruit number, always overestimating this variable with an average error equal to 38 fruits per square meter and a $\mathrm{d}$ value equal to 0.78 (Table 5). The error averaged over all experiments using the modified values was equal to 11 fruits per square meter and the average d value was 0.95 (Table 5). Averaged over all experiments, the RMSE was $71 \%$ lower using the modified values comparing with the default version. The reason for the large PODUR (pod addition duration) value is that the model computes this based on seed growth rate (demand) relative to assimilate supply. This constructed feature is unrealistic for crops with low THRESH (ratio of seed to fruit plus seed), but this was not modified as we wished to stay with the standard coding of the CROPGRO model.

Sensitivity analyses of CROPGRO-Tomato to temperature. It is important to evaluate model sensitivity to temperature after inputting these new literature values for cardinal temperatures and to evaluate for reasonable behavior of predicted life cycle, biomass accumulation, and fruit yield as affected by temperature. To implement this sensitivity analyses, we started with the reference climate from the Bradenton, FL, experiments (where the mean temperature over four growing seasons was $29 / 19{ }^{\circ} \mathrm{C}$ and the solar radiation was $21 \mathrm{MJ} \cdot \mathrm{d}^{-1}$ ). By comparison, the coolest environment of the 10 experimental seasons averaged $28 / 15^{\circ} \mathrm{C}$ (Tmax and Tmin) and the warmest (fall) environment averaged $32 / 21^{\circ} \mathrm{C}$. We then simulated a range of temperatures by steps of $3{ }^{\circ} \mathrm{C}$ using fixed temperature regimes of $20 / 10,23 / 13,26 / 16$, $29 / 19,32 / 22,35 / 25$, and $38 / 28^{\circ} \mathrm{C}$ Tmax and Tmin, maintaining the Tmax and Tmin differentials. Crop life cycle to maturity was shortest at the $29 / 19$ and $32 / 22{ }^{\circ} \mathrm{C}$, being particularly longer at the coolest temperatures (Fig. 11), which is consistent with literature (Adams et al., 2001; Adams and Valdez, 2002; Bertin, 2005). Both fruit yield and biomass declined with rising temperature (Fig. 11), but the fruit yield declined more rapidly, reaching zero at the $38 / 28{ }^{\circ} \mathrm{C}$ regime where biomass was only reduced $45 \%$ from the coolest to the warmest temperature. A long growth period was a significant contributor to greater fruit yield and higher biomass that occurred at cooler temperature, although photosynthetic reduction at warmer temperatures contributed to reduced biomass above $27^{\circ} \mathrm{C}$. Above $29 / 19^{\circ} \mathrm{C}$, poor fruit set contributed to lower fruit yield, as observed by progressively lower fruit harvest index above that temperature (data not shown). Simulated fruit size (average at maturity) was largest at coolest temperature $\left(15^{\circ} \mathrm{C}\right)$ and was reduced progressively as temperature increased (Fig. 11C). This is consistent with reports in the literature. Adams et al. (2001) found that fruit size was largest at 
Table 5. Root mean square error (RMSE) and Willmott d index for time-series simulations using default (D) as compared with modified (M) genetic parameter values.

\begin{tabular}{|c|c|c|c|c|c|c|c|c|c|c|c|c|c|c|c|c|}
\hline \multirow{2}{*}{ Experiment } & \multicolumn{4}{|c|}{ Leaf area index } & \multicolumn{4}{|c|}{ Aboveground biomass } & \multicolumn{4}{|c|}{ Total fruit weight } & \multicolumn{4}{|c|}{ Fruit number } \\
\hline & \multicolumn{2}{|c|}{ RMSE } & \multicolumn{2}{|c|}{ Willmott } & \multicolumn{2}{|c|}{ RMSE } & \multicolumn{2}{|c|}{ Willmott } & \multicolumn{2}{|c|}{ RMSE } & \multicolumn{2}{|c|}{ Willmott } & \multicolumn{2}{|c|}{ RMSE } & \multicolumn{2}{|c|}{ Willmott } \\
\hline$\overline{\text { BR91 }}$ & 0.91 & 0.41 & 0.9 & 0.98 & 447 & 380 & 0.99 & 0.99 & 678 & 421 & 0.95 & 0.97 & 42 & 16 & 0.70 & 0.90 \\
\hline BR94 & 1.10 & 0.96 & 0.92 & 0.93 & 1040 & 501 & 0.98 & 0.99 & 874 & 334 & 0.97 & 0.99 & 51 & 5 & 0.75 & 0.99 \\
\hline BR95 & 0.88 & 0.27 & 0.89 & 0.99 & 658 & 363 & 0.99 & 0.99 & 772 & 465 & 0.87 & 0.90 & ND & ND & ND & ND \\
\hline QU95 (S) & 0.97 & 0.37 & 0.95 & 0.97 & 886 & 617 & 0.97 & 0.98 & 629 & 419 & 0.97 & 0.97 & ND & ND & ND & ND \\
\hline QU95 (F) & 0.36 & 1.13 & 0.95 & 0.83 & 485 & 421 & 0.98 & 0.99 & 697 & 327 & 0.93 & 0.98 & ND & ND & ND & ND \\
\hline GA06 & 2.1 & 0.37 & 0.49 & 0.98 & 1849 & 513 & 0.86 & 0.98 & 302 & 130 & 0.98 & 0.99 & ND & ND & ND & ND \\
\hline GA07 & 1.66 & 0.48 & 0.79 & 0.96 & 656 & 642 & 0.99 & 0.99 & 667 & 487 & 0.79 & 0.98 & 37 & 13 & 0.78 & 0.97 \\
\hline Average & 1.07 & 0.60 & 0.86 & 0.94 & 755 & 487 & 0.97 & 0.99 & 616 & 398 & 0.93 & 0.97 & 38 & 11 & 0.78 & 0.95 \\
\hline
\end{tabular}

${ }^{2}$ Statistics using default parameters.

${ }^{y}$ Statistics using modified parameters.

$\mathrm{ND}=$ not done.
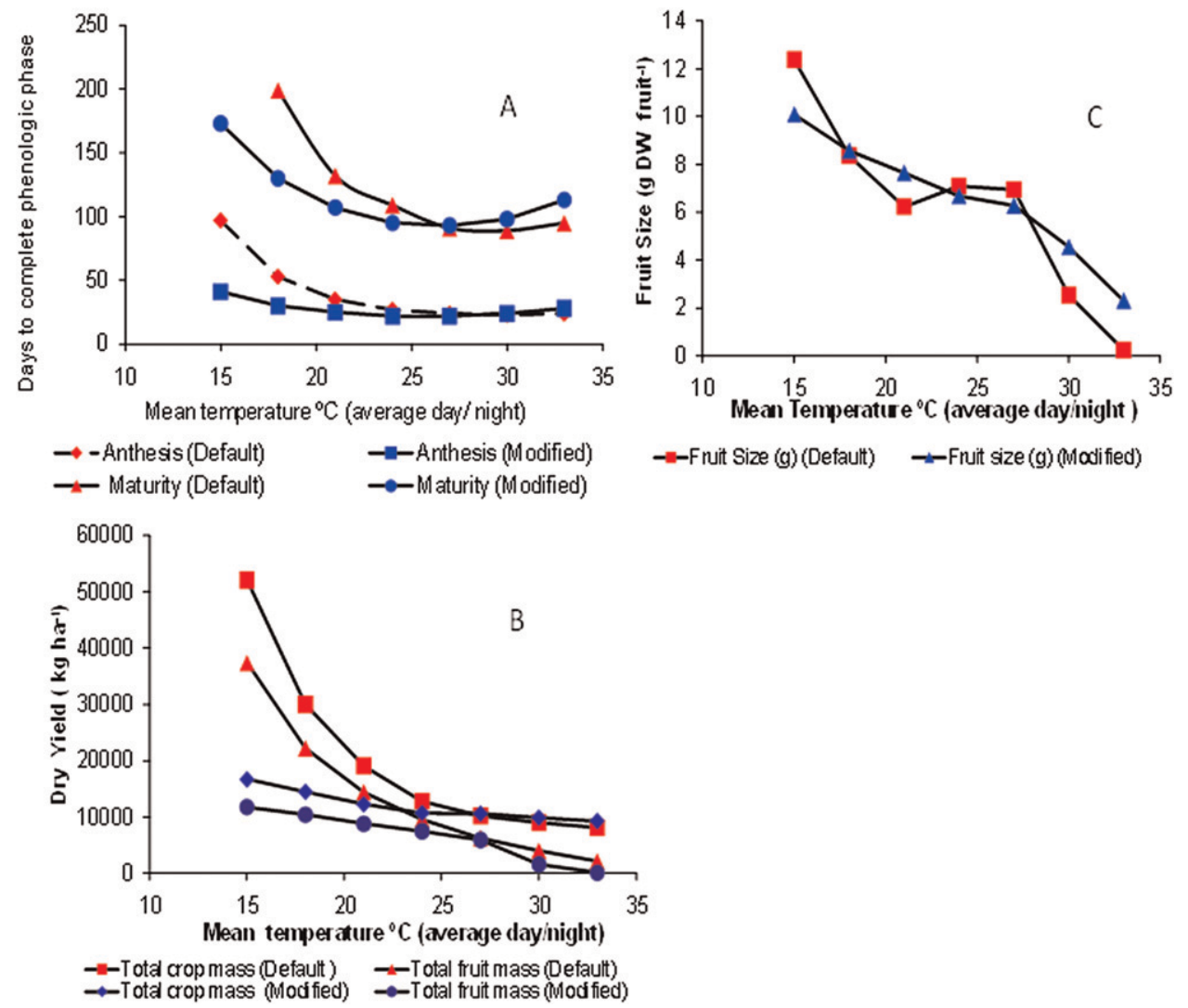

Fig. 11. Response of tomato development and yield to mean temperature. (A) Days to anthesis and maturity; (B) total crop mass and fruit dry matter yield; and (C) fruit size ( $\mathrm{g}$ dry weight per fruit) for simulations with modified model parameters vs. default model parameters. Simulations performed at constant solar radiation of $21 \mathrm{MJ} \cdot \mathrm{m}^{-2} \cdot \mathrm{d}^{-1}$ and constant day/night temperature regimes of: 20/10, 23/13, 26/16, 29/19, 32/22, 35/25, and 38/28 ${ }^{\circ} \mathrm{C}$ (graphed against mean temperature).

$18{ }^{\circ} \mathrm{C}$ and declined as temperature increased, because the effect of shorter fruit growth duration dominated the effect of a higher optimum temperature for fruit growth rate. De Koning (1996), likewise, found largest fruits at $17{ }^{\circ} \mathrm{C}$, decreasing to $23^{\circ} \mathrm{C}$.

In a comparison of modified to default parameters (Fig. 11), the life cycle simulated with the default model parameters appeared much too long at the cooler temperatures because the Scholberg et al. (1997) $\mathrm{T}_{\mathrm{b}}$ of $10{ }^{\circ} \mathrm{C}$ was too high. With default parameters, the unrealistically long life cycle also led to unrealistically high total biomass and fruit yield at the coolest temperature (Fig. 11), whereas the fruit yield was not reduced enough at high temperatures. The photosynthesis parameters for the default version are partly responsible for very high biomass and yield at cool temperature. So we conclude that the modified parameters are a major improvement over the default parameters for predicting biomass and fruit yield sensitivity to temperature. The new parameters caused a smoother, more desirable progression in fruit size simulations vs. temperature.
Time course simulations of total crop mass and cumulative fruit yield at different temperatures for the modified model illustrate the lags in biomass and total fruit growth that occur with either too cool or too warm temperature as well as the higher yield potential associated with longer life cycle at moderately cool temperature (Fig. 12A-B). Total fruit fresh weight prediction over time is a new output from this model (Fig. 12C) as well as fruit size of successive fruit cohorts over time. Fruit fresh weight prediction is based on the approach proposed by Boote and Scholberg 

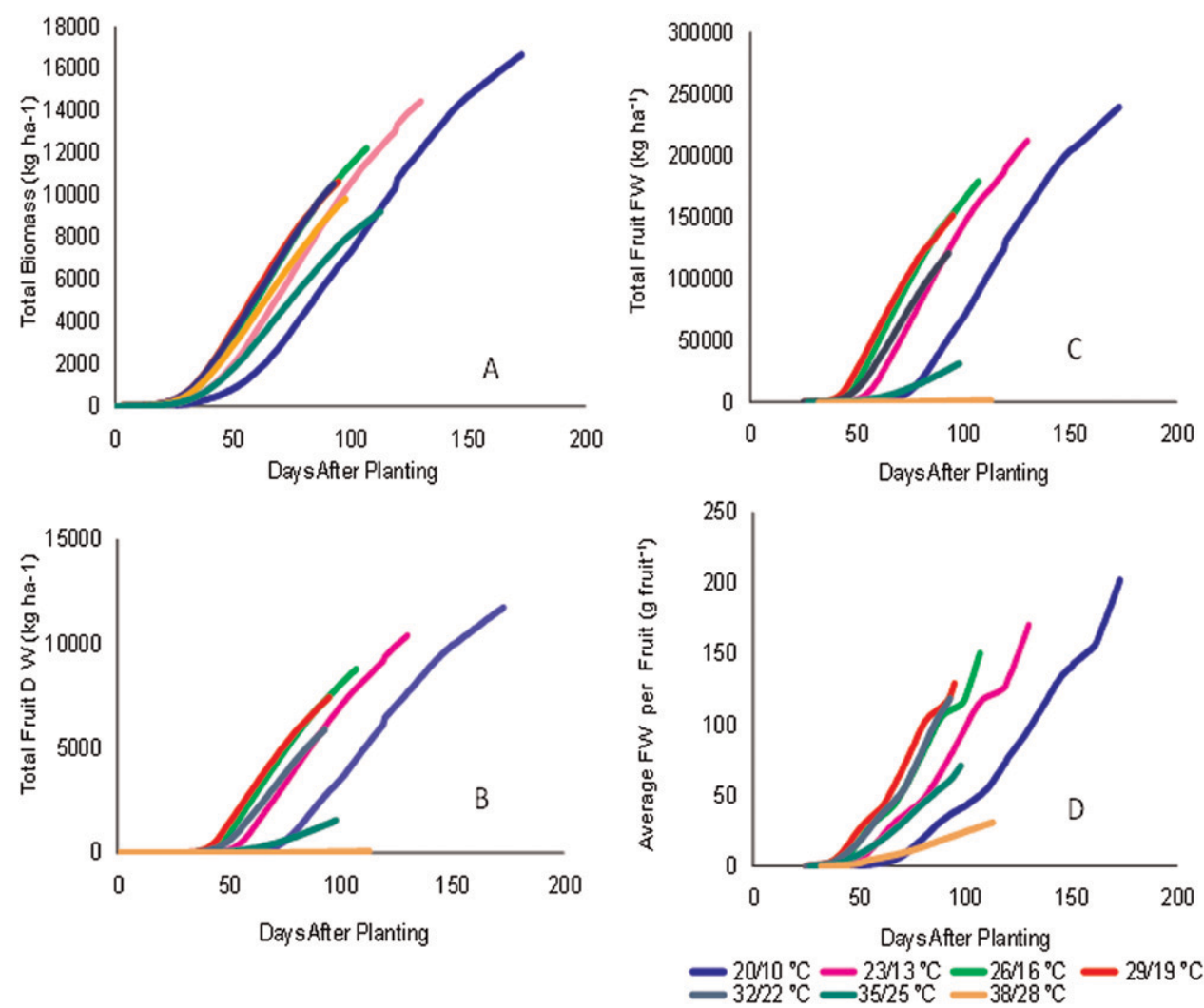

Fig. 12. Response of tomato yield variables over time at different day/night temperature average. (A) Total biomass; (B) total fruit dry weight; (C) total fruit fresh yield; and (D) single fruit average fresh weight for simulations with modified (M) model parameters. Simulations performed at constant solar radiation of 21 $\mathrm{MJ} \cdot \mathrm{m}^{-2} \cdot \mathrm{d}^{-1}$ and constant day/night temperature regimes of: $20 / 10,23 / 13,26 / 16,29 / 19,32 / 22,35 / 25$, and $38 / 28{ }^{\circ} \mathrm{C}$ (graphed against mean temperature).

(2006), in which percent DM concentration is predicted for individual fruits as a function of individual fruit thermal age and used to convert individual fruit dry weight to fresh weight and aggregated over all fruits. The average fresh weight per fruit over time is shown in Figure $12 \mathrm{D}$, but this does not adequately show that simulated early fruits are approximately twice as large as late-set fruits.

\section{Conclusions}

Overall, the ability of the CROPGROTomato model to simulate the time-series of LAI, leaf growth, total biomass, and fruit dry weight was significantly improved using the modified parameters compared with the default values. Therefore, we recommend using the newly calibrated values of the genetic crop and cultivar coefficients for the next release version (Version 4.5) of the CROPGROTomato model. The proposed adaptation is based on reliable values of cardinal temperatures from more recent literature and should improve the accuracy of the tomato biomass and yield predictions for correct response to climate change factors such as temperature and also assist efforts in future model applications to consider weather effects on tomato production.

To better predict growth and fruit production of indeterminate tomato (particularly for the greenhouse industry), the CROPGROTomato model should be further investigated with cultivars that have indeterminate growth.
The cardinal temperature values described in Table 1 are mostly from indeterminate cultivars and thus should be relevant. To this point, the model has only been calibrated with field data using semideterminate cultivars growing in open field and, therefore, assumptions regarding the indeterminate behavior of the model in greenhouses cannot be made until an appropriate evaluation is performed. The way in which the model simulates the number and growth of stems should be studied and improved along with improving control of the growth of other sinks on the plant. However, the feature of limiting partitioning (XFRUIT) to values such as 0.5 and the model's successive fruit addition and explicit fruit cohort structure should be very useful for greenhouse tomato simulations, because these processes in the model will allow extended vegetative growth as well as prediction of timing of successive fruit maturation.

\section{Literature Cited}

Abreu, P., J.F. Meneses, and C. Gary. 2000 Tompousse, a model of yield prediction for tomato crops: Calibration study for unheated plastic greenhouse. Acta Hort. 519:141-149.

Acock, B. 1991. Modeling canopy photosynthetic response to carbon dioxide, light interception, temperature and leaf traits, p. 41-55. In: Boote, K.J. and R.S. Loomis (eds.). Modeling crop photosynthesis from biochemistry to canopy. Crop Sci. Soc. of Amer., Spec. Pub. No 19. Amer. Soc. of Agron, Madison, WI.

Adams, S.R., K.E. Cockshull, and C.R.J. Cave. 2001. Effect of temperature on the growth and development of tomato fruits. Ann. Bot. (Lond.) 88:869-877.

Adams, S.R. and V.M. Valdez. 2002. The effect of periods of high temperature and manipulating fruit load on the pattern of tomato yields. HortScience 77:461-466.

Aikman, D.P. 1996. A procedure for optimizing carbon dioxide enrichment of a glasshouse tomato crop. J. Agr. Engr. 63:171-184.

Atherton, J.G. and G.P. Harris. 1986. Flowering, p. 167-200. In: Atherton, J.G. and J. Rudich (eds.). The tomato crop. A scientific basis for improvement. Chapman \& Hall, New York, NY.

Benedictos, P., Jr. and N. Yavari. 2000. Optimum sowing date in relation to flower drop reduction in tomato. Acta Hort. 533:351-357.

Bertin, N. 2005. Analysis of the tomato fruit growth response to temperature and plant fruit load in relation to cell division, cell expansion and DNA endoreduplication. Ann. Bot. (Lond.) 95:439447.

Bohner, J. and F. Bangerth. 1988. Effects of fruit set sequence and defoliation on cell number, cell size and hormone levels of tomato fruits (Lycopersicon eculentum Mill.) within a truss. J. Plant Growth Regul. 7:141-155.

Boote, K.J., J.W. Jones, and G. Hoogenboom. 1998. Simulation of crop growth: CROPGRO model, p. 651-692. In: Peart, R.M. and R.B. Curry (eds.) Agricultural systems modeling and simulation. Marcel Dekker, New York, NY.

Boote, K.J., J.W. Jones, G. Hoogenboom, and J. White. 2010. The role of crop systems simulation in agriculture and environment. Intl. J. Agr. \& Environ. Info. Syst. 1:41-54.

Boote, K.J., J.W. Jones, and N.B. Pickering. 1996. Potential uses and limitations of crop models. Agron. J. 88:704-716. 
Boote, K.J., M.I. Minguez, and F. Sau. 2002. Adapting the CROPGRO legume model to simulate growth of faba bean. Agron. J. 94:743-756

Boote, K.J. and N.B. Pickering. 1994. Modeling photosynthesis of row crop canopies. HortScience 29:1423-1434.

Boote, K.J. and J.M.S. Scholberg. 2006. Developing, parameterizing and testing of dynamic crop growth models for horticultural crops. Acta Hort. 718:23-34.

Buster, T.P. 1979. Soil survey of Marion County, Florida. Soil Conservation Service, Washington, DC.

Byrd, G.T., D.R. Ort, and W.L. Ogren. 1995. The effects of chilling in the light on ribulose-1-5bisphosphate carboxylase/oxygenase activation in tomato (Lycopersicon esculentum Mill.). Plant Physiol. 107:585-591.

Calado, A.M. and C.A.M. Portas. 1987. Base temperature and date of planting in processing tomatoes. Acta Hort. 200:185-193.

Cannell, M.G.R. and J.H.M. Thornley. 1998. Temperature and $\mathrm{CO}_{2}$ responses of leaf and canopy photosynthesis: A clarification using the nonrectangular hyperbola model of photosynthesis. Ann. Bot. (Lond.) 82:883-892.

Dayan, E., H. Van Keulen, J.W. Jones, I. Zipori, D. Shmuel, and H. Challa. 1993. Development, calibration and validation of a greenhouse tomato growth model. I. Description of the model. Agr. Syst. 43:145-163.

De Koning, A.N.M. 1993. Growth of tomato crop: Measurements for crop model validation. Acta Hort. 328:141-146.

De Koning, A.N.M. 1994. Development and dry matter distribution in glasshouse tomato: A quantitative approach. Doctoral diss., Wageningen Agricultural University, Wageningen, The Netherlands.

De Koning, A.N.M. 1996. Quantifying the responses to temperature of different plant processes involved in growth and development of glasshouse tomato. Acta Hort. 406:99-104.

De Koning, A.N.M. 2000. The effect of temperature, fruit load and salinity on development rate of tomato fruit. Acta Hort. 519:85-94.

Dorais, M., D.A. Demers, A. Papadopoulos, and W. van Ieperen. 2001. Greenhouse tomato fruit cuticle cracking, p. 163-168. In: Janick, J. (ed.). Horticultural reviews. Wiley, New York, NY.

Ferreira, M.E., J.P. Abreu, V.V. de Bianco, and A. Monteiro. 1997. Predicting phasic development of green beans for processing using a model with high temperature reduction of thermal time accumulation. Sci. Hort. 69:123-133.

Folker, E. 1979. Commercial production, p. 37-90. In: Folker, E. (ed.). The tomato. Study of the plant and the commercial production. Hemisferio Sur, Buenos Aires, Argentina.

Gary, C., A. Baille, M. Navarrete, and R. Epanet. 1997. TOMPOUSSE, un modele simplifie de prevision du rendement et du caliber de la tomate, p. 100-109. In: Baille, A. (ed.). Actes du seminaire de I'AIP intersectorielle "Serres," INRA, Avignon.

Gillaspy, G., H. Ben-David, and W. Gruissem. 1993. Fruits: A developmental perspective. Plant Cell 5:1439-1451.
Heuvelink, E. 1995. Growth, development and yield of a tomato crop: Periodic destructive measurements in a greenhouse. Sci. Hort. 61:77-99.

Heuvelink, E. 2005. Developmental processes, p. 53-83. In: Heuvelink, E. (ed.). Crop production science in horticulture, tomatoes. CABI, Cambridge, UK.

Heuvelink, E. and M. Dorais. 2005. Crop growth and yield, p. 85-144. In: Heuvelink, E. (ed.) Crop production science in horticulture, tomatoes. CABI, Cambridge, UK.

Hu, W.H., Y.H. Zhou, Y.S. Du, X.J. Xia, and J.Q. Yu. 2006. Differential response of photosynthesis in greenhouse- and field-ecotypes of tomato to long-term chilling under low light. Plant Physiol. 163:1238-1246.

Hurd, R.G. and C.J. Graves. 1984. The influence of different temperature patterns having the same integral in the earliness and yield of tomato. Acta Hort. 148:547-554.

Jones, J.W., G. Hoogenboom, C.H. Porter, K.J. Boote, W.D. Batchelor, L.A. Hunt, P.W. Wilkens, U. Singh, A.J. Gijsman, and J.T. Ritchie. 2003. The DSSAT cropping system model. Eur. J. Agron. 18:235-265.

Lambers, H., F.S. Chapin, III, and T.L. Pons. 1998. Effects of high temperature on photosynthesis, p. 58-59. In: Lambers, H., F.S. Chapin III, and T.L. Pons (eds.). Plant physiological ecology. Springer, New York, NY.

Langton, F.A. and K.E. Cockshull. 1997. Is stem extension determined by DIF or by absolute day and night temperatures? Sci. Hort. 69:229-237.

Lohar, D.P. and W.E. Peat. 1998. Floral characteristics of heat-tolerant and heat-sensitive tomato (Lycopersicon esculentum Mill.) cultivars at high temperature. Sci. Hort. 73:53-60.

Mapelli, S., C. Froba, G. Torti, and G. Zoressi. 1978. Relationship between set, development and activities of growth regulators in tomato fruits. Plant Cell Physiol. 19:1281-1288.

Marcelis, L.F.M., A. Elings, P.H.B. Visser, and E. Heuvelink. 2009. Simulating growth and development of tomato crop. Acta Hort. 821: 101-110.

Martin, B., D.R. Ort, and J.S. Boyer. 1981. Impairment of photosynthesis by chilling-temperatures in tomato. Plant Physiol. 68:329-334.

Monteith, J.L. 1977. Climate and the efficiency of crop production in Britain. London Phil. Trans. Royal Soc. 281:277-294.

Moore, E.L. and W. Thomas. 1952. Some effects of shading and parachloro-phenoxy acetic acid on fruitfulness of tomatoes. Proc. Amer. Soc. Hort. Sci. 60:289-294.

Ogweno, J.O., X.S. Song, W.H. Hu, K. Shi, J.H. Zhou, and J.Q. Yu. 2009. Detached leaves of tomato differ in their photosynthetic physiological response to moderate high and low temperature stress. Sci. Hort. 123:17-22.

Parton, W.J. and J.A. Logan. 1981. A model for diurnal variation in soil and air temperature. Agr. Met. 23:205-216.

Paz, J.O., C.W. Fraisse, L.U. Hatch, A. Garcia y Garcia, L.C. Guerra, O. Uryasev, J.G. Bellow, J.W. Jones, and G. Hoogenboom. 2007. Development of an ENSO-based irrigation support tool for peanut production in the southeastern US. Comput. Electron. Agr. 55:28-35.
Pearce, B.D., R.I. Grange, and K. Hardwick. 1993. The growth of young tomato fruit. I. Effects of temperature and irradiance on fruit grown in controlled environment. J. Hort. Sci. 68:111.

Perry, K.B., Y. Wu, D.C. Sanders, J.T. Garrett, D.R. Decoteau, R.T. Nagata, R.J. Dufault, K.D. Batal, D.M. Granberry, and W.J. Mclaurin. 1997. Heat units to predict tomato harvest in southeast USA. Agr. and For. Met. 84:249-254.

Rinaldi, M., D. Ventrella, and C. Gagliano. 2007. Comparison of nitrogen and irrigation strategies in tomato using CROPGRO model. A case study from southern Italy. Agr. Water Mgt. 87:91-105.

Rybak, M.R. 2009. Improving a tomato growth model to predict fresh weight and size of individual fruits. Doctoral diss., Graduate School of the University of Florida, Gainesville, FL.

Rylsky, I. 1979. Fruit set and development of seeded and seedless tomato fruits under diverse regimes of temperature and pollination. J. Amer. Soc. Hort. Sci. 104:835-838.

Scholberg, J., B.L. McNeal, K.J. Boote, J.W. Jones, S.J. Locascio, and S.M. Olson. 2000a. Nitrogen stress effects on growth and nitrogen accumulation by field-grown tomato. Agron. J. 92:159-167.

Scholberg, J., B.L. McNeal, J.W. Jones, K.J. Boote, C.D. Stanley, and T.A. Obreza. 2000b. Growth and canopy characteristics of field-grown tomato. Agron. J. 92:152-159.

Scholberg, J.M.S., K.J. Boote, J.W. Jones, and B.L. McNeal. 1997. Adaptation of the CROPGRO model to simulate the growth of field-grown tomato, p. 133-151. In: Kropff, M.J., P.S. Teng, P.K. Aggarwal, J. Bouma, B.A.M. Bouman, J.W. Jones, and H.H. van Laar (eds.). Systems approaches for sustainable agricultural development: Applications of systems approaches at the field level. Kluwer, Dordrecht, The Netherlands.

Van Der Ploeg, A. and E. Heuvelink. 2005. Influence of sub-optimal temperature on tomato growth and yield: A review. J. Hort. Sci. Biotechnol. 80:652-659.

Varga, A. and J. Bruinsma. 1986. Tomato, p. 461480. In: Monselise, S.P. (ed.). CRC handbook of fruit set and development. CRC Press, Boca Raton, FL.

Verkerk, K. 1955. Temperature, light and the tomato. Mededelingen van de Landbouwhogeschool, Wageningen, The Netherlands. 55:175-224.

Walker, A.J. and L.C. Ho. 1977. Carbon translocation in the tomato carbon import and fruit growth. Ann. Bot. (Lond.) 41:813-823.

Warnock, S.J. 1973. Tomato development in California in relation to heat unit accumulation. HortScience 8:487-488.

Warnock, S.J. and R.L. Isaacs. 1969. A linear heat unit system for tomatoes in California. HortScience 5:670-671.

Went, F.W. 1945. II. Thermoperiodicity in growth and fruit of tomato. Amer. J. Bot. 31:135-150.

Willmott, C.J. 1981. On the validation of models Phys. Geo. 2:184-194.

$\mathrm{Xu}$, H.L., R. Wang, L. Gauthier, and A. Gosselin. 1999. Tomato leaf photosynthetic responses to humidity and temperature under salinity and water deficit. Pedosphere 9:105-112. 